\title{
Inter-Comparison of Phytoplankton Functional Type Phenology Metrics Derived from Ocean Color Algorithms and Earth System
}

\section{Models}

Kostadinov, Tihomir S. ${ }^{1, *}$, Anna Cabré ${ }^{2, * *}$, Harish Vedantham ${ }^{3, * * *}$, Irina Marinov ${ }^{2}$, Astrid

Bracher $^{4}$, Robert J. W. Brewin ${ }^{5}$, Annick Bricaud ${ }^{6}$, Takafumi Hirata ${ }^{7}$, Toru Hirawake ${ }^{8}$, Nick J.

Hardman-Mountford ${ }^{9}$, Colleen Mouw ${ }^{10, * * * *}$, Shovonlal Roy ${ }^{11}$, Julia Uitz ${ }^{6}$

[1] Department of Geography and the Environment, Univ. of Richmond, 28 Westhampton Way, Richmond, VA 23173, USA. 
25 [11] Department of Geography and Environmental Science \& School of Agriculture, Policy and Development,

26 University of Reading, Whiteknights, Reading RG6 6AB, UK.

27

28 *Corresponding author: tkostadi@ @ichmond.edu

29 ** Now at Dept. of Physical and Technological Oceanography, Marine Science Institute, CSIC, Barcelona, Spain.

$30 * * *$ Now at Cahill Center for Astronomy and Astrophysics, California Institute of Technology, Pasadena, CA 91125,

31 USA.

$32 * * * *$ Now at University of Rhode Island, Graduate School of Oceanography, Narragansett, RI, 02882, USA

33

34 Keywords: phytoplankton bloom, phenology, phytoplankton functional types, microplankton,

35 ocean color algorithms, inter-comparison, CMIP5 Earth system models, Discrete Fourier

36 Transform.

37

38

39

40

41

42

43

44

45

46

47 
Abstract

49 Ocean color remote sensing of chlorophyll concentration has revolutionized our understanding of

50 the biology of the oceans. However, a comprehensive understanding of the structure and function

51 of oceanic ecosystems requires the characterization of the spatio-temporal variability of various

52 phytoplankton functional types (PFTs), which have differing biogeochemical roles. Thus, recent

53 bio-optical algorithm developments have focused on retrieval of various PFTs. It is important to

54 validate and inter-compare the existing PFT algorithms; however direct comparison of retrieved

55 variables is non-trivial because in those algorithms PFTs are defined differently. Thus, it is more

56 plausible and potentially more informative to focus on emergent properties of PFTs, such as

57 phenology. Furthermore, ocean color satellite PFT data sets can play a pivotal role in informing

58 and/or validating the biogeochemical routines of Earth System models. Here, the phenological

59 characteristics of 10 PFT satellite algorithms and 7 latest-generation climate models from the

60 Coupled Model Inter-comparison Project (CMIP5) are inter-compared as part of the International

61 Satellite PFT Algorithm Inter-comparison Project. The comparison is based on monthly satellite

62 data (mostly SeaWiFS) for the 2003-2007 period. The phenological analysis is based on the

63 fraction of microplankton or a similar variable for the satellite algorithms and on the carbon

64 biomass due to diatoms for the climate models. The seasonal cycle is estimated on a per-pixel

65 basis as a sum of sinusoidal harmonics, derived from the Discrete Fourier Transform of the

66 variable time series. Peak analysis is then applied to the estimated seasonal signal and the

67 following phenological parameters are quantified for each satellite algorithm and climate model:

68 seasonal amplitude, percent seasonal variance, month of maximum, and bloom duration.

69 Secondary/double blooms occur in many areas and are also quantified. The algorithms and the

70 models are quantitatively compared based on these emergent phenological parameters. Results 
71 indicate that while algorithms agree to a first order on a global scale, large differences among

72 them exist; differences are analyzed in detail for two Longhurst regions in the North Atlantic:

73 North Atlantic Drift Region (NADR) and North Atlantic Subtropical Gyre West (NASW).

74 Seasonal cycles explain the most variance in zonal bands in the seasonally-stratified subtropics at

75 about $30^{\circ}$ latitude in the satellite PFT data. The CMIP5 models do not reproduce this pattern,

76 exhibiting higher seasonality in mid and high-latitudes and generally much more spatially

77 homogeneous patterns in phenological indices compared to satellite data. Satellite data indicate a

78 complex structure of double blooms in the Equatorial region and mid-latitudes, and single blooms

79 on the poleward edges of the subtropical gyres. In contrast, the CMIP5 models show single

80 annual blooms over most of the ocean except for the Equatorial band and Arabian Sea.

81

82

83

84

85

86

87

88

89

90

91 


\section{1. Introduction}

93 Marine phytoplankton play an important role in the global carbon cycle via oxygenic

94 photosynthesis and the biological pump (Field et al., 1998; Eppley and Peterson, 1979;

95 Falkowski et al., 1998; IPCC, 2013; Siegel et al., 2014). Since the late 1990's, ocean color

96 remote sensing has enhanced our understanding of oceanic ecosystems via continuous global

97 estimates of total chlorophyll $a$ concentration (Chl), interpreted as a proxy for phytoplankton

98 biomass (e.g. McClain, 2009; Siegel et al., 2013). However, total Chl does not provide a full

99 description of the ecosystem. Phytoplankton have different morphological (size and shape) and

100 physiological (growth and mortality rates, response to nutrient, temperature and light conditions)

101 characteristics and different resulting biogeochemical and ecological roles (e.g. silica or iron

102 requirements, calcification, sinking rates, feeding characteristics) and are thus grouped

103 accordingly into phytoplankton functional types (PFTs, e.g. IOCCG 2014). Phytoplankton

104 community structure influences many fundamental components of the marine biogeochemical

105 cycle, including: phytoplankton physiology; nutrient uptake; nutrient cycling; growth rates;

106 metabolic rates; deep-ocean carbon export; and the transfer of energy through the marine food

107 web (IOCCG, 2014). Therefore, detailed characterization of PFTs, and not only total Chl, is

108 required to develop predictive understanding of the ocean's role in climate on various time scales

109 (e.g. Le Quéré et al., 2005; Hood et al., 2006; Stock et al., 2014) and inform climate models.

110 One of the primary distinguishing characteristics of the different PFTs is cell size, which is

111 considered to be a master trait (Marañón, 2015) and is correlated to first order with

112 biogeochemical function - e.g. Le Quéré et al, 2005). Size partitioning has been used as a first-

113 order proxy for PFT classification (e.g. Vidussi et al., 2001; Le Quéré et al., 2005; Uitz et al.,

114 2006; Kostadinov et al., 2010). 
116 Satellite remote sensing provides a comprehensive observation method to characterize the global

117 spatio-temporal distribution of PFTs (e.g. McClain et al. 2009; Siegel et al, 2013). Space-borne

118 platforms can provide continuous sampling at the required resolution in time and space in order to

119 facilitate the development of more complex "dynamic green ocean models" (Le Quéré et al.,

120 2005) that include multiple functional types and resolve important biogeochemical processes

121 (IOCCG, 2014, Ch. 1, Sect. 1.5). Multiple satellite bio-optical algorithms for the retrievals of

122 various PFTs have been developed in the last decade as a result. One class of algorithms is based

123 on total abundance and the premise that smaller cells are associated with oligotrophic conditions

124 whereas larger cells are associated with eutrophic conditions (Chisholm, 1992) - such algorithms

125 are described by Brewin et al. (2010), Hirata et al. (2011) and Uitz et al. (2006). Another class

126 of algorithms relies on various spectral features. The PHYSAT algorithm exploits second-order

127 anomalies of reflectance spectra (Alvain et al., 2005; Alvain et al., 2008), whereas several other

128 algorithms are based on either absorption (Bracher et al., 2009; Ciotti and Bricaud, 2006; Mouw

129 and Yoder, 2010; Roy et al, 2011; Roy et al 2013), or backscattering (Kostadinov et al., 2009;

130 Kostadinov et al., 2010; Kostadinov et al., 2016), or a hybrid of absorption and backscattering

131 (Fujiwara et al., 2011).

132

133 Brewin et al. (2011) conducted the first systematic inter-comparison of PFT algorithms designed

134 to identify "dominant" PFTs in the oceans. With the increasing publication of new PFT

135 algorithms (IOCCG, 2014), an international team of PFT algorithm developers and scientists was

136 tasked to perform a follow-up inter-comparison exercise (Hirata et al., 2012; Hirata, 2015); this

137 study reports results from a component of this inter-comparison project. A summary of the 
138 available algorithms and their technical basis can be found in Table 1 (also see IOCCG, 2014).

139 The various algorithms use different PFT definitions and retrieve different variables that are

140 based on various sets of assumptions, and hence are not necessarily directly comparable. Some

141 retrieve several taxonomic groups, others - size fractions based on Chl or volume (Table 1;

142 IOCCG 2014). PFT algorithms often aim to quantify the size structure of the phytoplankton

143 population by defining three phytoplankton size classes (PSCs) - picoplankton $(<2 \mu \mathrm{m})$,

144 nanoplankton $(2-20 \mu \mathrm{m})$, and microplankton $(>20 \mu \mathrm{m})$ (Sieburth et al., 1978). This is justified

145 because size is considered a master trait (e.g. Marañon et al. 2015), but we caution that

146 differences exist between PFTs and PSCs, even though this terminology is often used

147 interchangeably. 
148 Table 1. Overview of the PFT/PSC algorithms used and the relevant variable(s) from which phenological parameters

149 were derived. SW10 refers to SeaWiFS monthly mapped $9 \mathrm{~km}$ global $R_{r s}(\lambda)$ data for the 2003-2007 period. Monthly

150 data for 2003-2007 from SCIAMACHY on ENVISAT was only used for PhytoDOAS and has 1/2 degree spatial

151 resolution. The variables provided by most algorithm are dimensionless, i.e. fractions of a total, most commonly -

152 chlorophyll-a (Chl). This is indicated by a double dash in the table. If in situ data were used in algorithm development,

153 the region from which the data came is indicated. N/A means no in situ data were directly used in the algorithm

154 development (not including validation) (see references for details).

155

156

\begin{tabular}{|c|c|c|c|c|c|c|c|}
\hline $\begin{array}{c}\text { Algorithm } \\
\text { Publication(s) }\end{array}$ & Acronym & Variables Analyzed & Units & $\begin{array}{l}\text { Input } \\
\text { Data }\end{array}$ & $\begin{array}{l}\text { Algorithm } \\
\text { Class/Basis }\end{array}$ & $\begin{array}{l}\text { Variables } \\
\text { Retrieved }\end{array}$ & $\begin{array}{c}\text { Region of } \\
\text { development }\end{array}$ \\
\hline Alvain et al. $(2005,2008)$ & PHYSAT & $\begin{array}{c}\text { Frequency of } \\
\text { detection of diatoms }\end{array}$ & $\begin{array}{l}\% \text { of } \\
\text { days }\end{array}$ & SW10 & $\begin{array}{l}R_{r s}(\lambda) \text { second- } \\
\text { order anomalies } \\
\text { (Radiance-based) }\end{array}$ & $\begin{array}{c}\text { Multiple } \\
\text { taxonomic PFTs }\end{array}$ & $\begin{array}{c}\text { North Atlantic; } \\
\text { Equatorial \& Tropical } \\
\text { South Pacific; } \\
\text { Southern Ocean } \\
\end{array}$ \\
\hline $\begin{array}{l}\text { Bracher et al. (2009); } \\
\text { Sadeghi et al. (2012) }\end{array}$ & PhytoDOAS & Diatoms Chl & $\mathrm{mg} \mathrm{m}^{-3}$ & $\begin{array}{l}\text { SCIAM } \\
\text { ACHY }\end{array}$ & $\begin{array}{c}\text { Differential } \\
\text { absorption from } \\
\text { hyperspectral data. } \\
\text { (Absorption-based) }\end{array}$ & $\begin{array}{c}\text { Multiple } \\
\text { taxonomic PFTs }\end{array}$ & $\begin{array}{c}\text { Uses PFT-specific } \\
a_{p h}(\lambda)\end{array}$ \\
\hline Brewin et al. (2010) & BR10 & $\begin{array}{l}\text { Microplankton - } \\
\text { fraction of Chl }\end{array}$ & -- & SW10 & Abundance-based. & Size structure & Atlantic Ocean \\
\hline $\begin{array}{l}\text { Ciotti and Bricaud (2006), } \\
\text { Bricaud et al. (2012) }\end{array}$ & CB06 & $\begin{array}{c}1-S_{f} \text {, where } S_{f}= \\
\text { fraction of small } \\
\text { phytoplankton }\end{array}$ & -- & SW10 & Absorption-based. & Size structure & $\begin{array}{l}\text { Global (In situ data } \\
\text { used for picoplankton } \\
\text { basis vector) }\end{array}$ \\
\hline Fujiwara et al. (2011) & FUJI11 & $\begin{array}{l}\text { Microplankton - } \\
\text { fraction of Chl }\end{array}$ & -- & SW10 & $\begin{array}{l}\text { Absorption- and } \\
\text { backscattering- } \\
\text { based. }\end{array}$ & Size structure & Arctic-North Pacific \\
\hline Hirata et al. (2011) & OC-PFT & Microplankton - & -- & SW10 & Abundance-based. & Size structure & Global (coastal and \\
\hline
\end{tabular}




\begin{tabular}{|c|c|c|c|c|c|c|c|}
\hline $\begin{array}{c}\text { Kostadinov et al. (2009, } \\
\text { 2010) }\end{array}$ & KSM09 & $\begin{array}{c}\text { fraction of Chl } \\
\text { Microplankton - } \\
\text { volume fraction }\end{array}$ & -- & SW10 & $\begin{array}{c}\text { Backscattering- } \\
\text { based. }\end{array}$ & Size structure & shelf waters excluded) \\
\hline Mouw and Yoder (2010) & MY10 & $\begin{array}{c}S_{f m} \text { fraction of large } \\
\text { phytoplankton }\end{array}$ & -- & SW10 & Absorption-based. & Size structure & Global \\
\hline Roy et al. $(2011,2013)$ & ROY13 & $\begin{array}{c}\text { Microplankton - } \\
\text { fraction of Chl }\end{array}$ & -- & SW10 & Absorption-based. & Size structure & Global \\
\hline Uitz et al. (2006) & UITZ06 & $\begin{array}{c}\text { Microplankton- } \\
\text { fraction of Chl }\end{array}$ & -- & SW10 & Abundance-based. & Size structure & $\begin{array}{c}\text { Global (case-2 waters } \\
\text { excluded) }\end{array}$ \\
\hline O'Reilly et al. $(1998,2000)$ & OC4v6 & Chl-a & $\mathrm{mg} \mathrm{m}^{-3}$ & SW10 & $\begin{array}{c}\text { Band-ratio } R_{r s}(\lambda) \\
\text { based. } \\
\text { (Radiance-based) }\end{array}$ & Chl-a & Global \\
\hline
\end{tabular}


157 Here we compare the algorithm outputs in terms of a key emergent property: phytoplankton

158 phenology. Since seasonal cycles are a key property of ecosystems, it is important to assess to

159 what degree different algorithms agree in terms of phenology, i.e. how consistently they capture

160 the annual progression of phytoplankton blooming and subsequent senescence. If the timing of a

161 bloom were slightly shifted between two data sets, direct comparison of the variables at each time

162 step would yield disparate and meaningless results, whereas phenological analysis will identify

163 the offset in timing (Platt et al., 2009). The amount of algorithms spread about an ensemble

164 mean can be indicative of our confidence in retrieving a certain phenological parameter (e.g.

165 timing of annual bloom), and overall results of the comparison can guide further algorithm

166 improvements.

167

168 We use the Discrete Fourier Transform (DFT) to first model the seasonal cycle as a summation of

169 sinusoids derived from the annual frequency band and its harmonics (integer multiples). We then

170 quantify phenological parameters of interest using the modeled seasonal cycle. The phenology

171 inter-comparison is based on global ocean color data (SeaWiFS and SCIAMACHY) for the

172 period 2003-2007, using microplankton fraction or the most similar available variable from each

173 participating PFT/PSC algorithm (Table 1). Increases in the absolute or fractional amount of

174 large phytoplankton or diatoms were considered here to define a bloom, which is consistent with

175 the established ecological idea that higher chlorophyll concentrations are associated with

176 eutrophy and a relatively higher dominance of large phytoplankton (e.g. Chisholm, 1992; Loisel

177 et al., 2006; Kostadinov et al., 2010; Marañón, 2015). We quantify the timing, amplitude and

178 duration of blooms, as well as the fraction of variance explained by the modeled seasonal cycle.

179 We compare these phenological parameters among the PFT algorithms. The same phenological 
180 parameters are also compared for the NASA chlorophyll product (OC4v6 Chl), as well as

181 contemporary diatom carbon biomass provided by seven CMIP5 Earth System Models (ESMs).

182 Our goal is not to rank the satellite algorithms and CMIP5 models in terms of quality; rather we

183 strive to identify spatial patterns of agreement and disagreement among the algorithms in an

184 effort to guide future improvements. Additionally, the comparison to the ESM ensemble is aimed

185 at guiding future improvements in biogeochemical and climate modeling, a key goal of the Earth

186 system science community (IPCC, 2013).

\section{2. Data and Methods}

\subsection{Input Satellite Data}

189 All algorithms with the exception of PhytoDOAS use monthly global $9 \mathrm{~km}$ Level 3 mapped

190 SeaWiFS remote-sensing reflectance, $\left(R_{r s}(\lambda)\right.$, reprocessing R2010.0) from January 2003 to

191 December 2007 as input (60 monthly maps total). These data as well as the corresponding

192 monthly OC4v6 Chl data (O'Reilly et al., 2000) and monthly composites of daily averaged

193 photosynthetically available radiation (PAR, mol photons $\mathrm{m}^{-2} \mathrm{day}^{-1}$ ) from the same reprocessing

194 were downloaded from the NASA Ocean Biology Distributed Active Archive Center

195 (OB.DAAC) maintained by the Ocean Biology Processing Group (OBPG)

196 (http://oceandata.sci.gsfc.nasa.gov/) (NASA Goddard Spaceflight Center, 2010). $R_{r s}(\lambda)$ data were

197 processed by the individual algorithm providers. The hyperspectral PhytoDOAS algorithm is

198 based on Scanning Imaging Absorption Spectrometer for Atmospheric Cartography

199 (SCIAMACHY) level-1 top-of-atmosphere radiance data. SCIAMACHY was a satellite sensor

200 with a native pixel size is $30 \mathrm{~km}$ by $60 \mathrm{~km}$ which operated from 2002 to 2012 on the ENVISAT

201 satellite. These processing details were agreed upon by the International PFT Inter-comparison 
Project Team (Hirata et al., 2012). SeaWiFS Chl data were analyzed in the same way as the PFT

203 algorithms data for comparison purposes. PAR data were used for verification of the DFT

204 phenological algorithm (Supplement Part 1).

205

\subsection{PFT/PSC Algorithm Output Pre-Processing}

207 The PFT/PSC algorithms were used to derive phenological parameters using the variable most

208 closely corresponding to either microplankton $\mathrm{Chl}\left[\mathrm{mg} \mathrm{m}^{-3}\right]$ or microplankton/large

209 phytoplankton fraction [\% of total Chl]. The rationale behind this choice is 1) blooming/more

210 eutrophic conditions are on average characterized by an increase in total and fractional large

211 phytoplankton biomass; and 2) this is the most common variable among all available algorithms.

212 Table 1 summarizes the respective variables used in the phenological analysis, indicates the

213 acronym used here for each algorithm and provides additional relevant information. For

214 additional algorithm methodologies details, see the references in Table 1 and IOCCG (2014).

216 Monthly data from all algorithms were down-sampled to 1 degree resolution using two-

217 dimensional convolution with a $12 \times 12$ top hat averaging kernel $(2 \times 2$ in the case of

218 PhytoDOAS due to its different resolution). Missing data in the original resolution were ignored

219 in the averaging; however, if less than $50 \%$ of the pixels being averaged were valid data, the pixel

220 in the down-sampled image was assigned a missing data value. For PhytoDOAS, even a single

221 valid pixel of the four being averaged produced a valid pixel in the down-sampled image. The

222 registration of PhytoDOAS images was changed from grid/node to cell/pixel (NCEI, 2015) in

223 order to match all other down-sampled imagery. All variables were down-sampled in linear space

224 with the exception of $\mathrm{Chl}$ and the PhytoDOAS data, which were down-sampled in log10 space, 
since Chl values tend to vary lognormally spatially (Campbell, 1995). The log space spatial

226 average was weighted appropriately for any present zeros, which cannot participate in a log

227 average (Habib, 2012). Note that taking an arithmetic average in log space approximates the

228 median of the data in linear space (Campbell, 1995).

$230 \quad$ 2.3 Phenological Parameters via Discrete Fourier Transform (DFT); Metrics of

231 Algorithm and Model Inter-comparison.

232 An increase in the absolute or fractional amount of large phytoplankton or diatoms is considered

233 a bloom, and the bloom peak is considered the maximum of these values, respectively. A time

234 series of each algorithm's relevant microplankton or diatom variable (Table 1) was constructed at

235 each pixel at 1-degree resolution. Data were gap-filled temporally by linear interpolation (no

236 extrapolation was applied). If more than $45 \%$ of the data points were missing or if there was a

237 continuous run of missing data longer than 8 months anywhere in the time series, data for that

238 pixel was not used in the analysis. The mean was subtracted from each time series. Interannual

239 variability is not explicitly considered in this study; however, possible secular trends are removed

240 by detrending (by subtracting a least-squares line fit to the data), and other interannual variability

241 in the study period of 2003-2007 is taken into account implicitly because the DFT is computed

242 over the entire time series. If data were missing at the edges of the time series, they were filled

243 with zeros. The DFT was then used to transform the time series to the frequency domain. The

244 Fourier coefficients at a frequency of one cycle per year $\left(f=1 \mathrm{yr}^{-1}\right)$ and all its available harmonics

245 (integer multiples) were used to model the seasonal cycle as a sum of sinusoids of varying phases

246 and amplitudes. Supplement Part 1 describes the details of the DFT analysis and seasonal cycle

247 modeling, and Supplement Fig. S1 illustrates an example modeled seasonal cycle. 
249 Peak analysis was performed on the modeled annual cycle signal using the MATLAB® (R2014b)

250 Signal Processing Toolbox ${ }^{\circledR}$ routine findpeaks in order to determine the timing of the local

251 maxima, the signal height (the value of the signal at the peak) and the width of the signal at half-

252 height. The modeled signal minimum value was subtracted from the signal before peak analysis

253 to ensure correct height determinations. Signal edge effects were taken into account. In order to

254 avoid detection of small secondary peaks (many of which can be artifacts of the modeling), only

255 peaks whose prominence was greater than $10 \%$ of the signal range (maximum minus minimum

256 value) and which were at least 2.5 months apart from each other were detected. Prominence here

257 is equivalent to topographic prominence and can be thought of as the intrinsic height of the peak

258 relative to other nearby peaks. The same phenological analysis was applied to diatom carbon

259 output from 7 CMIP5 models - details of the methodology and model information are provided

260 in Supplement Part 2 and in Cabré et al. (2015). The following phenological parameters and

261 inter-comparison metrics were derived from the peak analysis for both the PFT algorithms and

262 the CMIP5 models:

264 1) Seasonal amplitude of the primary bloom, determined as half the height of the most prominent

265 (highest) peak (Supplement Fig. S1), was inter-compared qualitatively because variables are on

266 different scales (even among algorithms that have the same units, the methodologies are

267 different).

268 2) The month of maximum of the primary bloom, determined as the month where the DFT-

269 modeled seasonal cycle is maximum. The ensemble mean for the algorithms and CMIP5 models

270 (calculated separately for each ensemble) was used to quantitatively compare the month of 
maximum of each algorithm to the ensemble mean month of maximum for all algorithms. We

272 also compared the Chl and the ensemble mean CMIP5 model months of maxima. Variances in

273 month of maxima were quantified for the algorithms and the CMIP5 models separately. The

274 month of maximum was averaged across algorithms and models using circular statistical methods

275 to ensure a properly estimated mean and variance (Supplement Part 3).

276 3) Duration of the primary bloom (in days), determined as the width of the most prominent peak

277 at the peak's half-height level. Ensemble mean and standard deviation of bloom duration were

278 calculated for the CMIP5 models and algorithms, and individual algorithm durations were

279 qualitatively compared.

280 4) Percent seasonal variance, i.e. fraction of the data variance explained by the modeled seasonal

281 cycle as opposed to other processes (e.g. one-time events, multiannual processes, and inter-annual

282 variability due to climate oscillation modes like ENSO) and noise. An area in which this fraction

283 is very high is characterized by a very clean seasonal signal i.e. little variance contribution by

284 other processes. It is calculated as the sum of power at $f=1 \mathrm{yr}^{-1}$ and its harmonic frequencies

285 (Supplement Part 1), divided by total variance of the input data. The ensemble mean among the

286 algorithms and models was calculated.

288 At least three algorithms (or two CMIP5 models) were required to participate in the ensemble

289 means of month of maximum, percent seasonal variance and bloom duration for the ensemble

290 statistics to be considered valid. If present, the second most prominent peak, representing a

291 possible secondary bloom, was also characterized by using the above phenological parameters

292 and the following was also derived: difference in months between the primary and secondary

293 bloom, and relative prominence of the secondary blooms (ratio of the prominence of the 
294 secondary peak to the prominence of the primary peak). The fraction of satellite algorithms or

295 CMIP5 models exhibiting two annual peaks was mapped, indicating in which regions the

296 majority of algorithms or models agree that there is a secondary bloom. The difference in months

297 between the maxima of the primary and secondary blooms was compared qualitatively among the

298 algorithms. Finally, regionally binned analysis was performed for the following Longhurst

299 (1998) provinces 1) Westerlies - North Atlantic Drift - NADR and 2) North Atlantic Subtropical

300 Gyre West - NASW. Available data in these regions were spatially averaged and the resulting

301 single time series per region and algorithm/model were analyzed. Methodological details of this

302 analysis are provided in Supplement Part 4.

\section{3. Results and Discussion}

\section{$304 \quad 3.1$ Seasonal Amplitude}

305 The seasonal amplitude (Fig. 1) of the relevant PFT variables (Table 1) quantifies the strength of

306 the seasonal cycle at a particular location. The tropical ocean and the oligotrophic subtropical

307 gyres (defined here as the regions delineated by the climatological SeaWiFS Chl $=0.08 \mathrm{mg} \mathrm{m}^{-3}$

308 isoline and having Chl values less than this value) were generally characterized by low seasonal

309 amplitudes of $\mathrm{Chl}$ and microplankton across all the algorithms. However, according to most

310 algorithms, the southern edge of the South Pacific gyre, at around $30^{\circ} \mathrm{S}$, was characterized by a

311 band of higher seasonal amplitude, particularly evident in the UITZ06 and ROY13 data. Notably,

312 in BR10 and UITZ06, some of the areas of lowest amplitude for microplankton are just

313 equatorward of the Chl isoline delineating the gyre. Similarly, in ROY13 the gyres are not

314 actually the places with the lowest amplitudes; rather they occur just equatorward of them in the

315 Pacific. According to most algorithms, the highest seasonal amplitudes occur at the temperate 
316 and subpolar latitudes and in coastal zones, particularly the North Atlantic, the Northwestern

317 Pacific, and in the monsoon-driven upwelling region off of the Arabian Peninsula. Circumpolar

318 bands of high and low seasonal amplitude characterize the Southern Ocean, but the spatial details

319 of the bands differ across algorithms. Overall, the large-scale spatial patterns of seasonal

320 amplitude are similar, across algorithms of the same type. The CB06 algorithm retrieved almost

321 no valid data over the gyres, and the PHYSAT data sparsity precludes meaningful DFT analysis

322 over most areas; thus no PHYSAT map was included in Fig. 1 and subsequent maps (See Sect 3.6

323 for regionally binned analyses of PHYSAT data). 

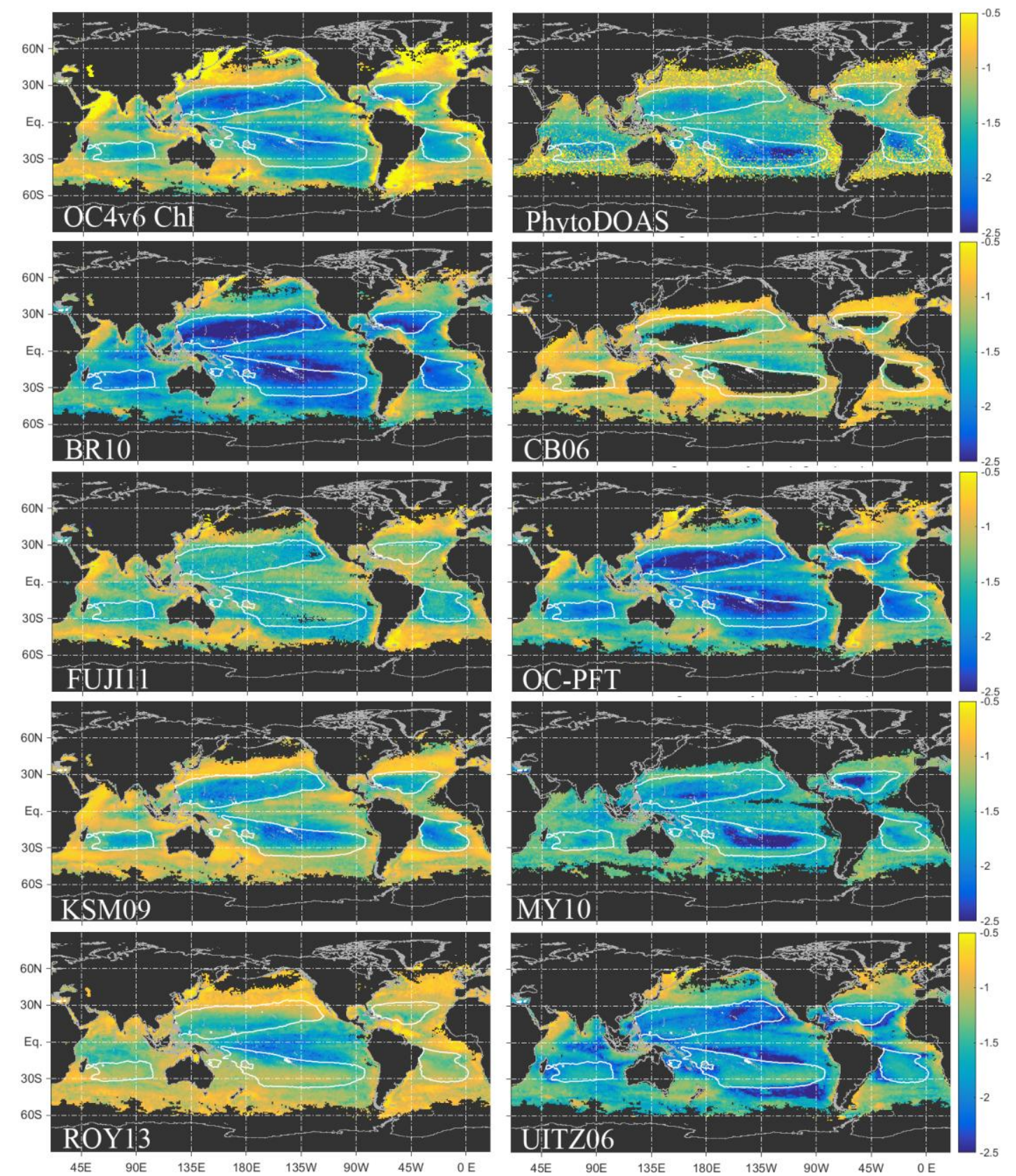

326 Figure 1. Seasonal amplitude of $\mathrm{Chl}$ and the large phytoplankton/diatoms variables of 9

327 PFT satellite ocean color algorithms (Table 1). PHYSAT is not shown due to data

328 sparsity. The same logarithmic color scale applies to all maps, and units are as 
329 indicated in Table 1. The isoline of climatological $\mathrm{Chl}=0.08 \mathrm{mg} \mathrm{m}^{-3}$ is plotted as a solid

330 white contour. All pixels where valid phenological analysis was performed are mapped.

331

\section{$332 \quad 3.2$ Percent Seasonal Variance}

333 The ensemble-mean percent seasonal variance for all 10 PFT algorithms (Fig. 2A) reveals several

334 oceanic zones where the seasonal cycle is particularly clean/reproducible. This is especially

335 prominent at the poleward boundaries of the subtropical gyres, around $30-40^{\circ}$ latitude in both

336 hemispheres, where $70-80 \%$ of the signal variability is explained by the seasonal cycle

337 represented by the DFT. These highly-seasonally variable regions correspond to sharp transitions

338 in surface Chl concentration, as observed in in situ observations and satellite data (e.g. Glover et

339 al. 1994). In the Pacific this feature is known as the transition zone chlorophyll front (TZCF),

340 which migrates from $30-35^{\circ} \mathrm{N}$ in winter to $40-45^{\circ} \mathrm{N}$ in summer; its migration is due primarily to

341 wind-driven seasonal variations in Ekman pumping and Ekman advection of nutrients (e.g.,

342 Bograd et al. 2004). The equivalent North Atlantic seasonally-stratified subtropics coincide with

343 the mid-latitude biome of Levy et al. (2005) and are described as a nutrient-limited regime.

344 Equivalent seasonally-stratified, nutrient-limited subtropics with high seasonal variability are

345 present in the Southern Ocean band around $30^{\circ} \mathrm{S}$. 

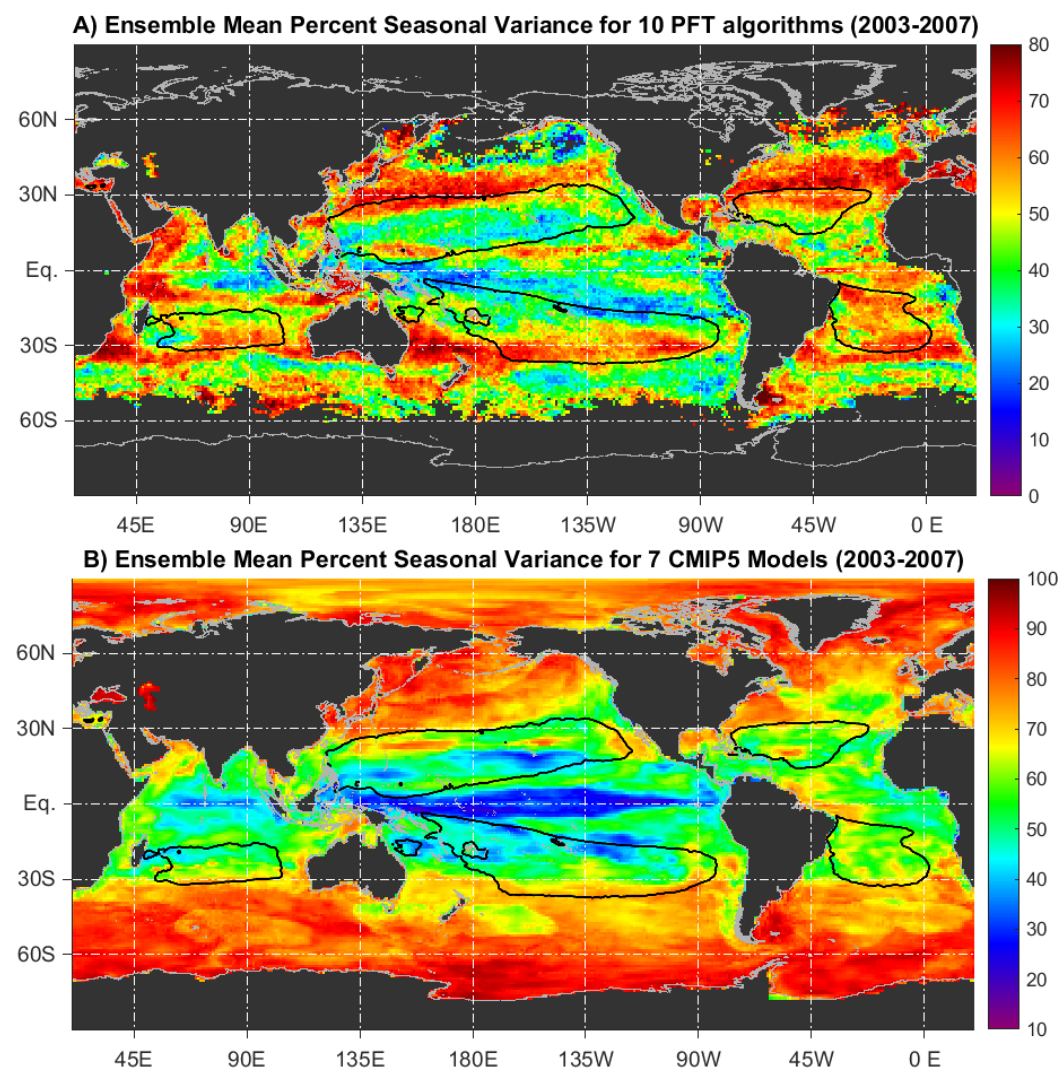

C) Ensemble Data - Ensemble Model Percent Seasonal Variance Differece, \%

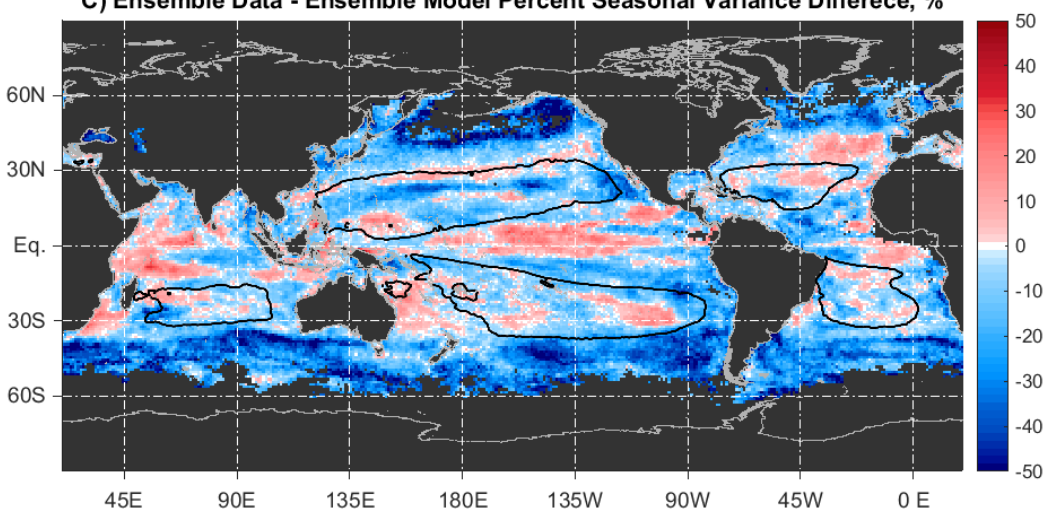

$\begin{array}{lllllllll}45 \mathrm{E} & 90 \mathrm{E} & 135 \mathrm{E} & 180 \mathrm{E} & 135 \mathrm{~W} & 90 \mathrm{~W} & 45 \mathrm{~W} & 0 \mathrm{E}\end{array}$

349 Figure 2. Ensemble mean percent seasonal variance for the 2003-2007 period for A)

350 the 10 PFT algorithms (Table 1) and B) the 7 CMIP5 models (Table S1). (C) The

351 difference in percent seasonal variance between the satellite data and the models

352 (positive difference means satellite data percent seasonal variance is larger than the

353 model value). The isoline of climatological $\mathrm{Chl}=0.08 \mathrm{mg} \mathrm{m}^{-3}$ is plotted as a solid black

354 contour. 
356 Detailed analysis of the KSM09-based carbon biomass from SeaWiFS (Kostadinov et al., 2016)

357 and CMIP5 model output shows that the regions of high percent seasonal variance of Fig. 2A

358 exhibit strong and reproducible seasonality and are mainly dominated by nano- and

359 microphytoplankton during the bloom months, and by picophytoplankton during the low-biomass

360 summer months (Cabré et al. 2016). These ensemble mean PFT-based results are consistent

361 with the Chl-based analysis of Sapiano et al. (2012) who also determined that the poleward

362 fringes of the subtropical gyres have the best seasonality statistical fits

364 In contrast to the satellite data, CMIP5 model diatom biomass exhibits smoother spatial

365 variability of percent variance explained by the seasonal cycle (Fig. 2B, model ensemble mean;

366 Fig 2C, model-data difference map), with much broader regions characterized by more than $60 \%$

367 of variance due to the annual cycle. The percent variance explained by the seasonal cycle is a

368 much stronger function of latitude (and hence the seasonality of insolation) in models. Poleward

369 of $40^{\circ} \mathrm{S} / 40^{\circ} \mathrm{N}$, models show stronger seasonal variance compared to satellite data. In contrast, the

370 Equatorial regions, especially in the Pacific and Indian Oceans, have lower percent annual

371 variance as compared to the satellite data.

372

\section{$373 \quad 3.3$ Month of Maximum of the Primary Bloom}

374 The ensemble-mean month of maximum of the primary peak (Fig. 3A) varies as a function of

375 latitude to first order, due to the seasonality of insolation, which is a primary physical driver of

376 oceanic ecosystems, controlling both light and nutrient availability (via heating rates, wind

377 patterns and mixing). This latitudinal dependence is most pronounced in the North Atlantic, 
378 where the subtropics experience a late winter-early spring bloom, northern temperate latitudes

379 experience maximum blooms in May and June, and subarctic regions - as late as August.

380 Equivalently, for much of the Southern Hemisphere subtropical seas, the maximum of the bloom

381 occurs in late austral winter - July and August (Fig. 3A). The Southern Ocean blooms later

382 during austral late spring and summer, mostly in November through February. However, the

383 Southern Ocean exhibits an interesting banded structure where large phytoplankton

384 (microplankton, diatoms) bloom earlier (November and December) in a zonal band around $50^{\circ} \mathrm{S}$,

385 as compared to a nearly continuous band just to the north, at about $45^{\circ} \mathrm{S}$, which tends to bloom

386 later in January and February. 


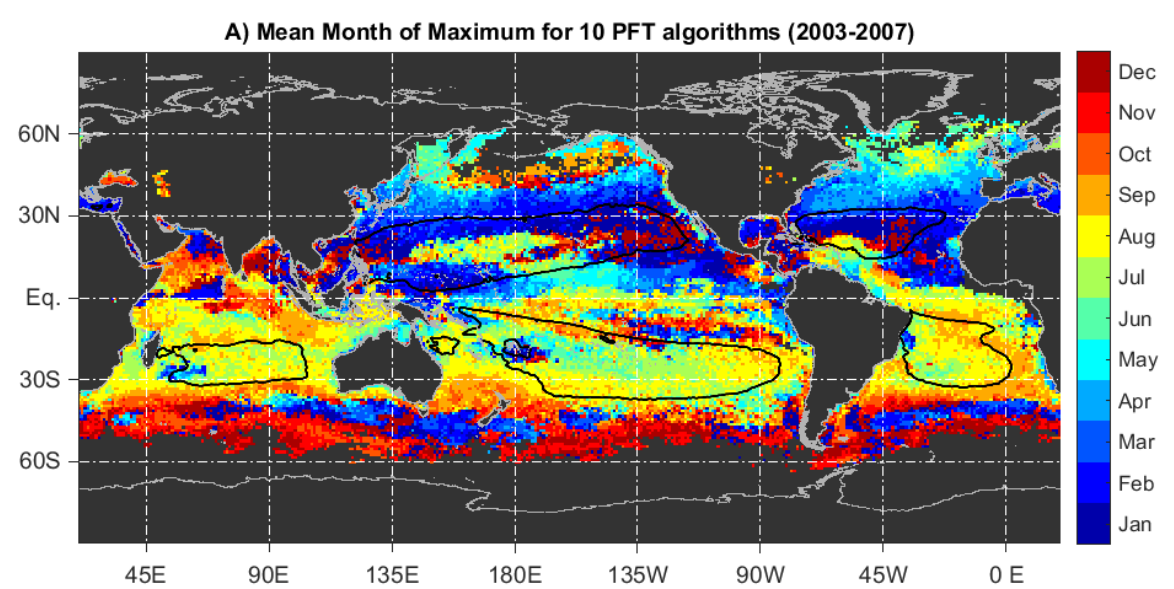

B) Mean Month of Maximum for 7 CMIP5 models (2003-2007)

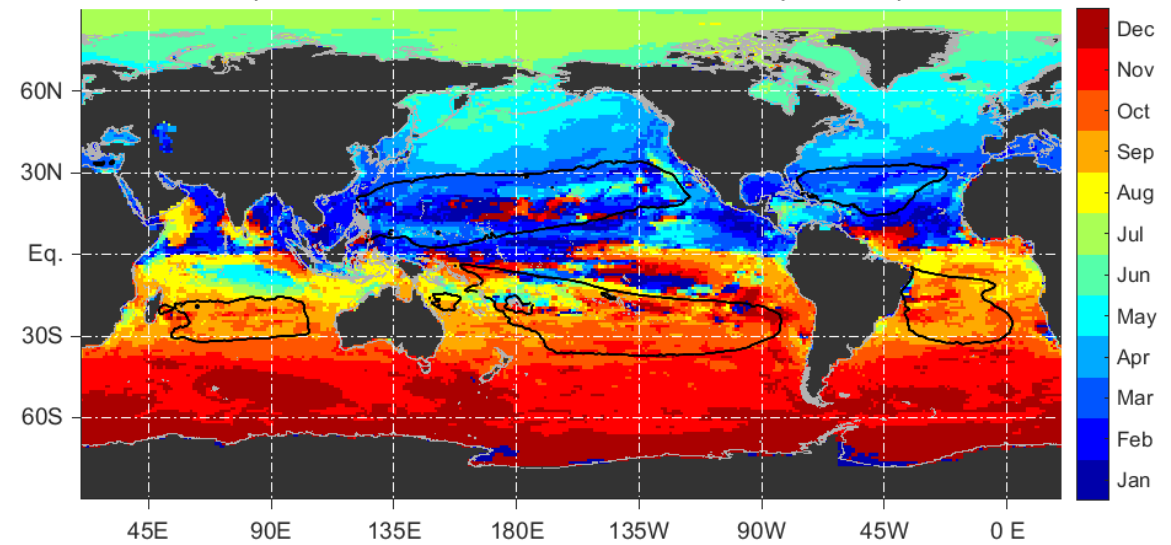

C) Ensemble Data - Models Month of Max Difference, +ve when Data leads

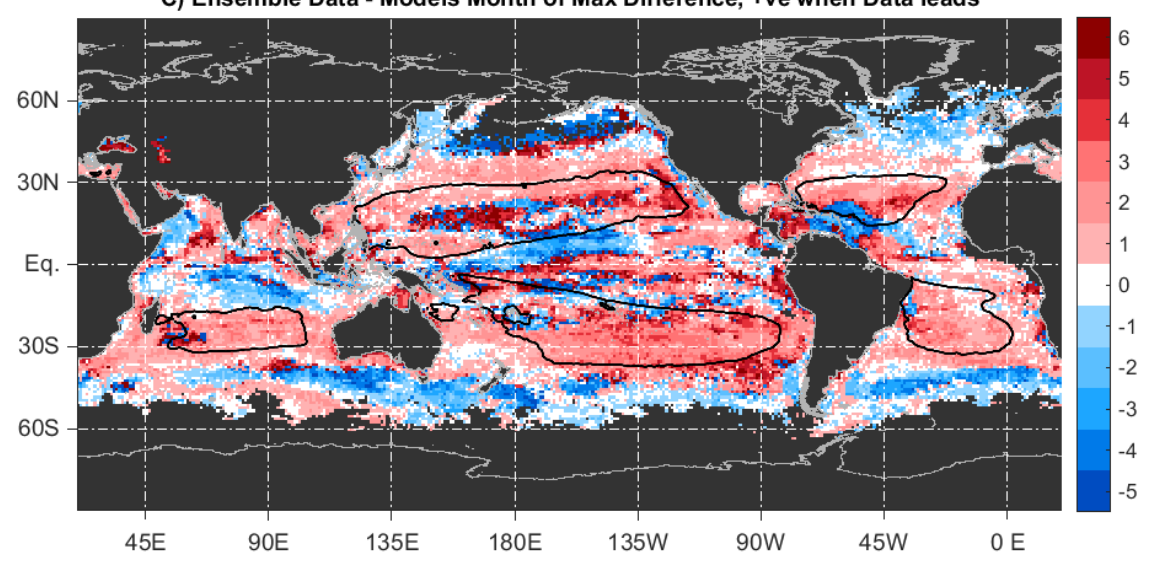

388 Figure 3. Ensemble mean month of maximum of A) fraction large phytoplankton/diatoms

389 (or Chl) among 10 PFT satellite algorithms (Table 1), and B) diatom biomass among 7

390 CMIP5 models. C) The difference (in months) between the ensemble means of the

391 satellite data and the models. A positive difference means the satellite data is leading 
392 the models, i.e. the bloom peak occurs earlier in the data than in the model. The isoline

393 of climatological $\mathrm{Chl}=0.08 \mathrm{mg} \mathrm{m}^{-3}$ is shown (black solid contour). The means and the

394 respective difference should be treated with caution in areas where a considerable

395 number of algorithms or models exhibit low fraction of variance explained by the

396 seasonal cycle (See. Supplement Fig. S13).

397

398 The CMIP5 ensemble mean month of maximum of diatom carbon biomass (Fig. 3B) exhibits a

399 similar spatial pattern with latitude and is spatially less noisy than the satellite PFT estimates. In

400 general the models place the blooms later in time over most of the ocean, as indicated by the

401 algorithm-model difference map (Fig. 3C, red colors indicate the data peak leads the model peak

402 in time). Notable exceptions are some areas in or near the subtropical gyres, the Equatorial

403 Upwelling, and the higher latitudes (e.g. the models do not reproduce the aforementioned banded

404 structure in the Southern Ocean), where models place the blooms earlier in time. The algorithm-

405 model difference is about one month over much of the ocean area (Fig. 3C, pale red or blue).

406 This difference is not randomly distributed and exhibits definite spatial patterns, pointing to

407 latitudinal biases in processes and understanding of seasonality in models.

408

409 The differences between the PFT algorithm's ensemble mean month of maximum and the month

410 of maximum for $\mathrm{Chl}$ are small (Supplement Fig. S2, top left panel), indicating that the PFT

411 algorithm ensemble mean month of maximum for microplankton (or similar variable, Table 1)

412 appears to be representative of that for total Chl. Several algorithms (BR10, OC-PFT, UITZ06)

413 are abundance-based (Table 1), i.e. their PFT retrievals are a strong function of Chl; thus it is not

414 surprising that their individual differences with the Chl month of maximum are relatively small. 
415 So the ensemble mean month of maximum may be driven by the abundance-based PFT

416 algorithms. Two of the spectral-based models (CB06 and MY10) also exhibit generally small

417 differences with the Chl results. Differences among other algorithms with respect to the month of

418 maximum can be larger; while for most of the ocean and for most algorithms the differences are

419 not very large, considerable discrepancies persist in significant ocean areas where month of

420 maxima difference can reach up to 5 or 6 months. More details, including possible reasons for

421 the observed differences, are discussed in Supplement Part 5. An alternative way to quantify the

422 level of agreement among the satellite algorithms or the CMIP5 models is the circular variance of

423 the month of maxima (Supplement Fig. S3). Note that in areas where percent seasonal variance

424 is low (Fig. 2A and Supplement Fig. S13), the concept of month of maximum for the seasonal

425 cycle breaks down and results in these areas should be interpreted with caution. See Sect. 3.7 and

426 this Supplement Part 9 for details.

428 We note that from a resource management standpoint, a difference of a month can be very

429 significant, especially with respect to the effect on higher trophic levels. For example, Platt et al.

430 (2003) conclude that differences of three weeks in the timing of the spring algal bloom can have

431 large influences on the survival index of fish larvae in the Northwest Atlantic. Koeller et al.

432 (2009) discuss the coupling of the phenologies of phytoplankton and shrimp in the North

433 Atlantic. In general, whether a difference of one or two months among the algorithms and

434 CMIP5 models is significant for practical applications will depend on the specific application.

435 Which PFT algorithm or algorithm ensemble may be best suited to inform a certain decision will

436 also depend on the issue at hand, as the algorithms have different theoretical bases. However, in 
general, practical applications would best be addressed by using daily or 8-day data, rather than

438 the monthly data used here for the global inter-comparison.

\section{$440 \quad 3.4$ Primary Bloom Duration}

441 The ensemble mean of the duration of the primary annual bloom among the 10 PFT algorithms

442 (Fig. 4A) indicates that over much of the ocean the bloom duration is about $100-120$ days, i.e.

443 about 3-4 months. Maximum durations tend to occur at the poleward and to a lesser extend, the

444 equatorward fringes of the subtropical gyres. These maximum bands are most prominent in the

445 Pacific. Large portions of the interior of the southern hemisphere subtropical gyres also exhibit

446 long bloom duration. These results are consistent to first order with the SeaWiFS Chl-based

447 phenological analysis of Racault et al. (2012) and Sapiano et al. (2012), who use different

448 methodologies. Sapiano et al. (2012) observe longer bloom durations than the analysis here.

449 They note that their results are indeed longer than most previous studies and also caution that in 450 areas of double blooms, their duration indicates the combined duration of the blooms in some

451 cases. Additionally, our analysis may exhibit shorter durations if there is a taxonomical

452 succession, as our analysis indicates the bloom of only microplankton/diatoms. Sapiano et al.

453 (2012) note that bloom durations do not tend to exhibit a simple pattern of decrease with higher

454 latitudes, which is consistent with our observations (Fig. 4A), and different from the result of

455 Racault et al (2012). The PFT ensemble mean exhibits high spatial frequency noise, and there is

456 no clear pattern of decreasing bloom duration with increasing latitude. The same is noted by

457 Sapiano et al. (2012) and is also apparent in the analysis of Racault et al. (2012) to some degree,

458 but note that they use a coarser spatial smoothing. Maps of primary bloom duration for Chl and

459 the individual PFT algorithms are shown in Supplement Fig. S4 and agreement among the 
460 algorithms and CMIP5 models is quantified by the variance in primary bloom duration

461 (Supplement Fig. S5); additional details are discussed in Supplement Part 6.

462

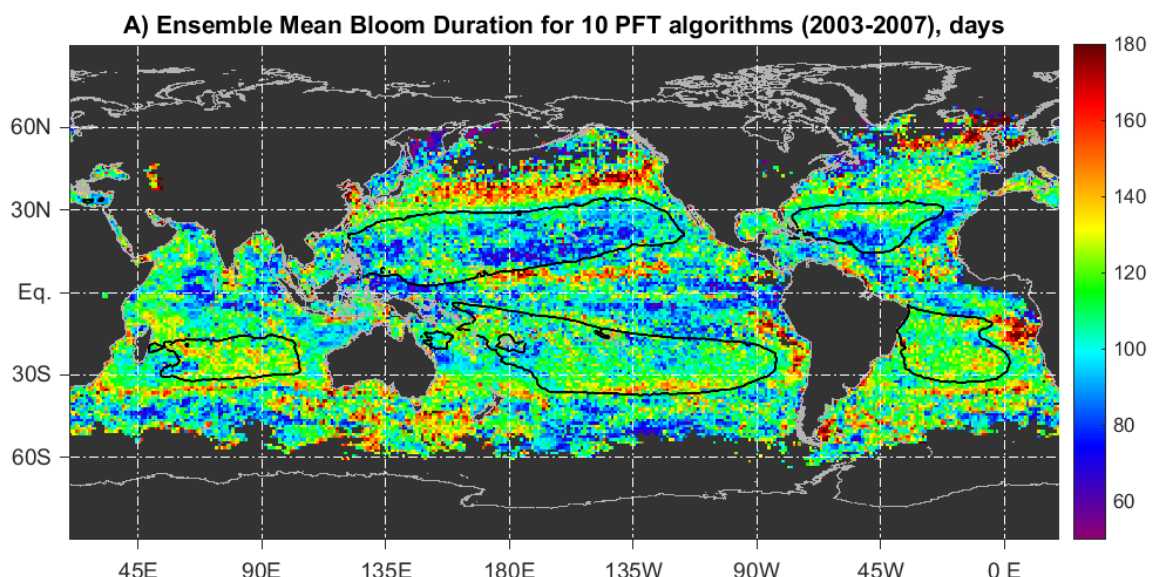

B) Ensemble Mean Bloom Duration for 7 CMIP5 Models (2003-2007), days

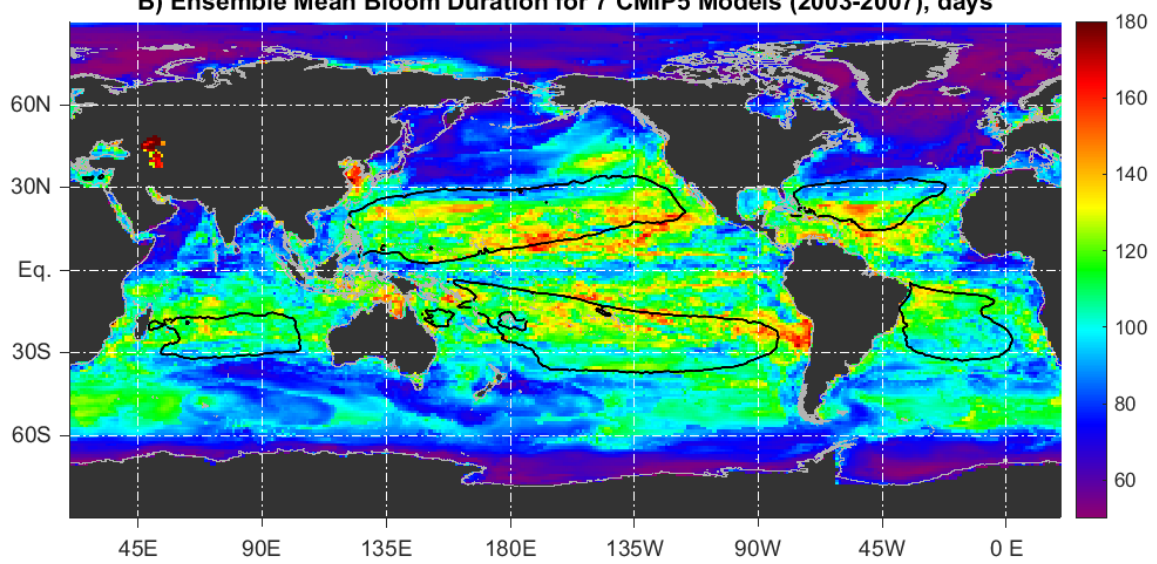

C) Ensemble Data - Ensemble Model Duration Difference, days

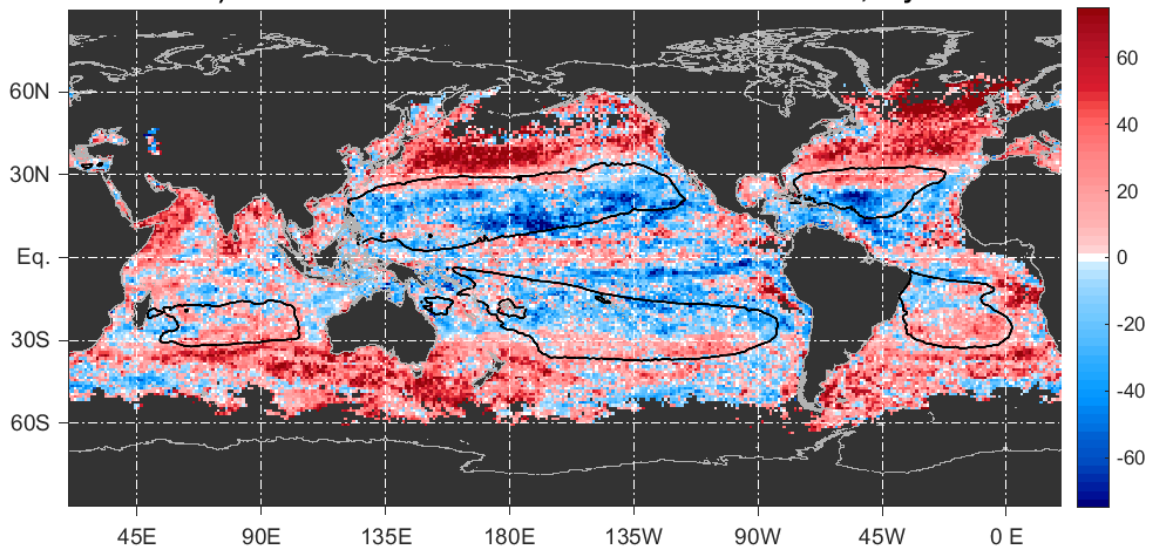

463 
464 Figure 4. Ensemble mean primary bloom duration (in days) for A) large

465 phytoplankton/diatoms among 10 PFT satellite algorithms, and B) diatom biomass

466 among 7 CMIP5 models. C) Difference in bloom duration between the satellite data and

467 the models (positive when data bloom duration is larger). Duration is defined as the

468 width of the modeled seasonal signal at half the bloom peak height. The isoline of

469 climatological $\mathrm{Chl}=0.08 \mathrm{mg} \mathrm{m}^{-3}$ is shown (black solid contour).

470

471 The CMIP5 models, in contrast to the PFT algorithm data, exhibit much smoother bloom duration

472 spatially (Fig. 4B), and the most prominent duration maxima occur at the equatorward fringes and

473 inside of the subtropical gyres. Compared to the satellite data, the higher latitudes exhibit a much

474 more obvious progression towards shorter bloom durations, dropping to below 2 months for polar

475 latitudes. Models fail to capture secondary peaks, which are especially important at high

476 latitudes, as explained in the following section. The lack of secondary peaks might contribute to a

477 shorter and cleaner definition of bloom duration in models when compared to data. The

478 difference in bloom duration between the models and the data (Fig. 4C) confirm that in general,

479 models exhibit longer blooms in the gyres and shorter bloom at latitudes higher than $\sim 30^{\circ}$.

\section{$480 \quad 3.5$ Secondary Blooms}

481 The presence of secondary blooms can be detected, because several harmonics were used in the 482 DFT analysis (Sect. 2.3 and Supplement Sect. S1). In the mid-latitudes, the second bloom is 483 usually a secondary bloom of smaller amplitude in the respective hemisphere's autumn (e.g.

484 Sapiano et al, 2012). To summarize the PFT algorithm and model consensus about where 485 secondary blooms occur, the fraction of algorithms that exhibit a single annual peak (Fig. 5A) 486 versus a double annual peak (Fig. 5B) is employed. Both maps exhibit well-defined latitudinal 
banding, where most algorithms exhibit a single peak at the poleward fringes of the subtropical

488 gyres ( $30^{\circ}$ latitude), a double peak around $40-45^{\circ}$ in both hemispheres, and again a single peak

489 at higher sub-polar latitudes of about $60^{\circ}$. Previous studies have identified and studied this

490 pattern, using Chl data (Sapiano et al., 2012) together with ecosystem modeling (Platt et al.,

491 2009). Cushing (1959) qualitatively described a single peak at higher latitudes and a double peak

492 at lower temperate latitudes, which is consistent with the PFT observations summarized here, as

493 well as the ecosystem model of Platt et al. (2009). Chl time series from SeaWiFS in the North

494 Atlantic analyzed in Platt et al. (2009) are also generally consistent with these observations, as is

495 the analysis of Cabré et al. (2016). In general the zonal bands of single vs. double peak run

496 slightly SW to NE in the Northern Hemisphere, which is most pronounced in the Pacific and is

497 apparent in both the analyses here (Fig.5A) and the maps of Sapiano et al. (2012). Importantly,

498 caution should be employed when interpreting results from areas with low seasonal variance

499 (Sect. 3.7, Figs. 2A and S13A). More details on the secondary blooms in the PFT data sets,

500 including phase difference with the respective primary bloom and fractional prominence analysis,

501 are provided in Supplement Part 7.

502

503 The CMIP5 models exhibit a very different pattern of single (Fig. 5C) vs. double peaks (Fig. 5D),

504 as compared to the PFT and Chl satellite data. Double peaks are predominantly found only along

505 the Equator and in the Arabian Sea and the Bay of Bengal. In these areas the models are in

506 agreement with the satellite data (cf. Figs. 5A and 5B), although the data are noisier. Models fail

507 to reproduce the secondary peak occurring at mid-latitudes around $40-45^{\circ}$ in satellite data. 508 


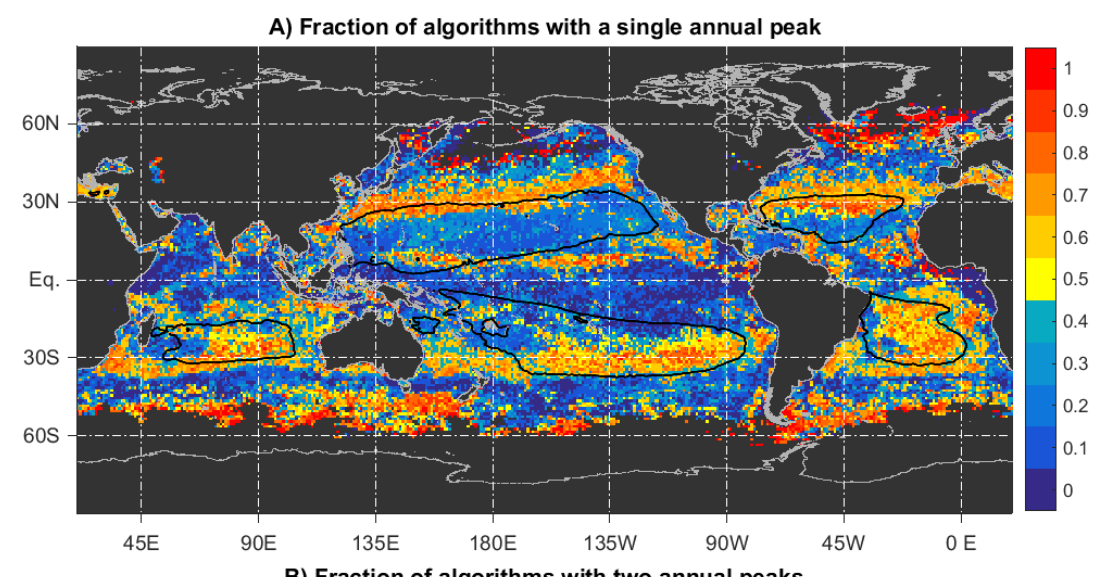

B) Fraction of algorithms with two annual peaks

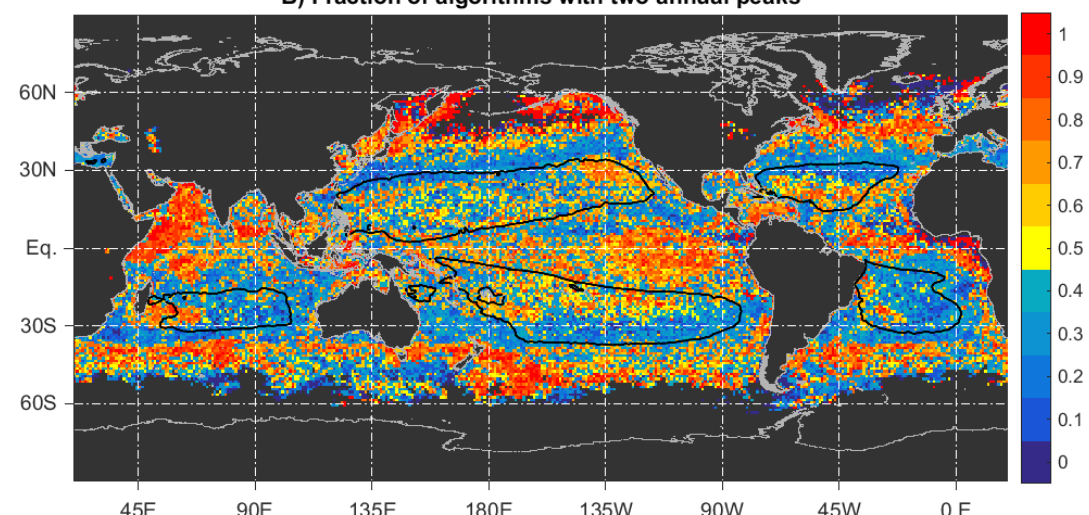

$\begin{array}{llllll}45 E & 90 E & 135 E & 180 E & 135 \mathrm{~W} & 90 \mathrm{~W} \\ & \text { C) Fraction of CMIP5 models with a single annual peak }\end{array}$

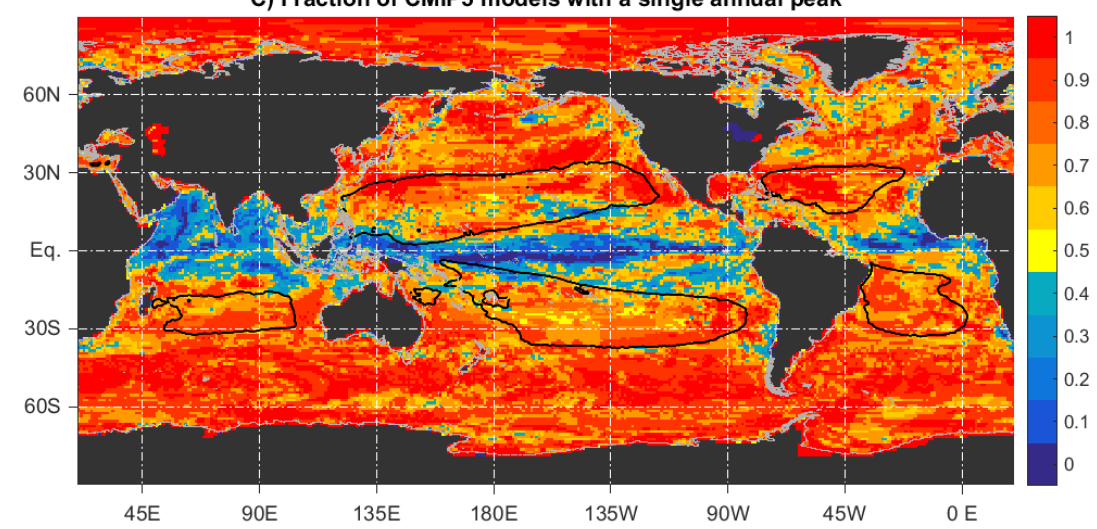

D) Fraction of CMIP5 models with two annual peaks

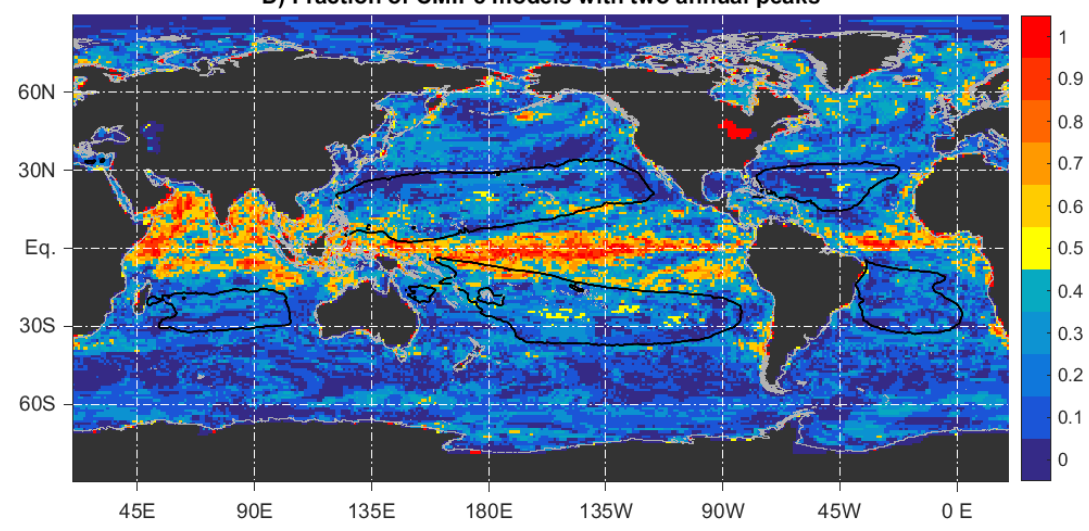


510 Figure 5. Fraction of PFT algorithms exhibiting (A) a single annual peak or (B) two

511 peaks in one annual cycle. Fraction of CMIP5 algorithms that exhibit (C) a single annual

512 peak and (D) two peaks in one annual cycle. The fraction is calculated from all

513 algorithms (or models, respectively) that have valid phenology metrics calculated at each

514 pixel (Supplement Fig. S6). The isoline of climatological $\mathrm{Chl}=0.08 \mathrm{mg} \mathrm{m}^{-3}$ (black solid

515 contour) is shown on all panels.

516

\section{$517 \quad 3.6$ North Atlantic Regionally Binned Analysis}

518 The analyses of seasonal variance (Fig. 2) and that of number of peaks (Fig. 5) suggest the

519 presence of the following North Atlantic biomes with significant seasonal amplitude: (a) a

520 subpolar regime north of about $50^{\circ} \mathrm{N}$, with a single (June to August) light-limited biomass peak;

521 and (b) a transitional, subpolar-subtropical regime between $35^{\circ}-50^{\circ} \mathrm{N}$ with two annual peaks,

522 resulting from an alternation of light and nutrient limited conditions (e.g. Evans and Parslow

523 (1985), and (c) a seasonally varying Northern subtropics regime centered around $30^{\circ} \mathrm{N}$,

524 characterized by a single annual peak in winter or early spring and high seasonal variability.

525 Monthly averages from regionally-binned satellite PFT time series for two Longhurst marine

526 biogeographic provinces, the North Atlantic Drift Region (NADR) and the North Atlantic

527 Subtropical gyre - West (NASW) (Supplement Fig. S9), are exhibited in Fig. 6A and 6B,

528 respectively. The NADR province straddles the subpolar and the transitional regimes

529 (representing mostly the transitional biome), whereas NASW represents the Northern subtropics

530 regime. The corresponding month of maxima are illustrated for the same Longhurst provinces for

531 the 10 PFT algorithms and Chl (Fig. 7A-B) and for the 7 CMIP5 models (Fig. 7C-D). The time

532 series in both regions (Fig. 6) illustrate that the PFT algorithms exhibit different absolute values 
533 and amplitudes/ranges of their variables (Table 1), even if they are mostly referred to as

534 large/micro phytoplankton. This is expected since the algorithms have differing theoretical bases.

535 The spectra of the corresponding complete 5-year time series (Supplement Fig. S10) have their

536 strongest peak at $f=1 \mathrm{yr}^{-1}$, indicating that the annual seasonal cycle is a first order source of

537 variability. $2^{\text {nd }}$ and $3^{\text {rd }}$ harmonics often represent additional notable peaks.

538

539 

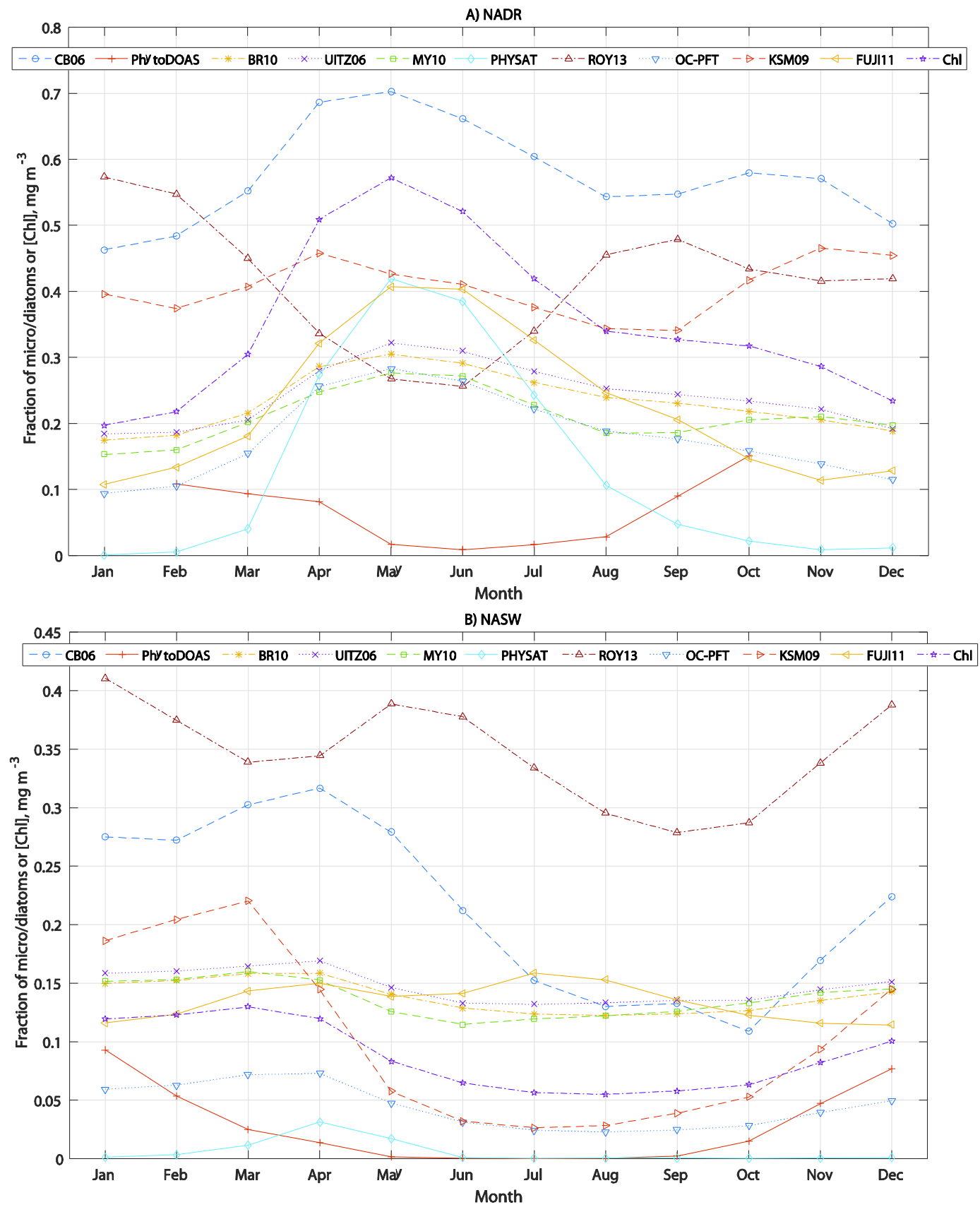

540

Figure 6. Time series plots of the monthly climatologies of the PFT algorithm variables

542 and OC4v6 Chl (units given in Table 1) and for two example Longhurst (1998)

543 biogeographic provinces as follows: A) North Atlantic Drift Region (NADR); B) The

544 Western North Atlantic Subtropical Gyral Province (NASW). Y-axis scales are different 
between the two panels. See Sect. 3.6 and Supplement Parts 4 and 8 for more

546 information and Supplement Fig. S9 for a map of the provinces.

547

548 Most algorithms in Longhurst's NADR province (Supplement Fig. S9) agree that there is a well

549 pronounced annual maximum in May (Figs. 6A, 7A); however ROY13 and PhytoDOAS indicate

550 minima then instead, exhibiting very different phasing of the seasonal cycle. Also KSM09

551 exhibits relatively small range of the seasonal cycle there compared to other algorithms, as well

552 as a double peak in April and November (Fig. 7A). The reasons for the lack of complete

553 agreement among the PFT algorithms regarding the month of maximum could not be resolved by

554 this study and require further investigation; this suggests that more in situ validation and

555 algorithm development data is required. Three of the seven CMIP5 models also place the

556 maximum in May (Fig. 7C), but for some it is in April or June, and December for the GISS-E2-

557 H-CC model, resulting in a higher variance of month of maximum for the models as compared to

558 the satellite data for NADR (cf. length of black arrows in Figs. 7A and 7C). Some inter-model

559 and data-model differences could be due to the relatively small size of the Longhurst provinces

560 with respect to the coarse model resolutions and the fact that some models may place the

561 equivalent biome in a different location due to different model physics. The NADR province

562 straddles regions where most satellite algorithms indicate double peaks (Figs. 5A and 5B); while

563 CMIP5 models show single annual peaks (Fig. 5C). The fall peak in satellite data is generally

564 weaker than the spring one (Fig. 6A); CB06, KSM09 and MY10 exhibit more noticeable fall

565 blooms. Note that these fall peaks may or may not be detected by the DFT analysis here based on

566 prominence criteria (Sect. 2.3). The presence of double peaks is reflected in the spectra having a

567 pronounced peak at $\mathrm{f}=2 \mathrm{yr}^{-1}$ (Supplement Fig. S10) that is almost as high as the primary peak at 
$568 \mathrm{f}=1 \mathrm{yr}^{-1}$. The NADR spectra indeed exhibit higher overall variance (more power) than the

569 NASW spectra, and also more even distribution of power between the annual and semi-annual

570 peaks, indicating the NASW area is characterized by a single annual peak, and NADR has a fall

571 secondary peak. The strength of this peak in relation to the primary one may depend on the unit

572 (fractional vs. absolute) used in the time series analysis (Sect 3.7 and Supplement Part 7). The

573 high variance of NADR is expected, as this area is known for its spectacular North Atlantic

574 blooms in the spring (e.g. Siegel et al., 2002; Behrenfeld, 2010). Since NADR straddles two

575 different regimes with respect to single vs. double peaks (cf. Figs. 5A and 5B and Supplement

576 Fig. S9), this analysis illustrates the limitations of a regionally binned approach using classically

577 defined biogeographic provinces.

578

579 

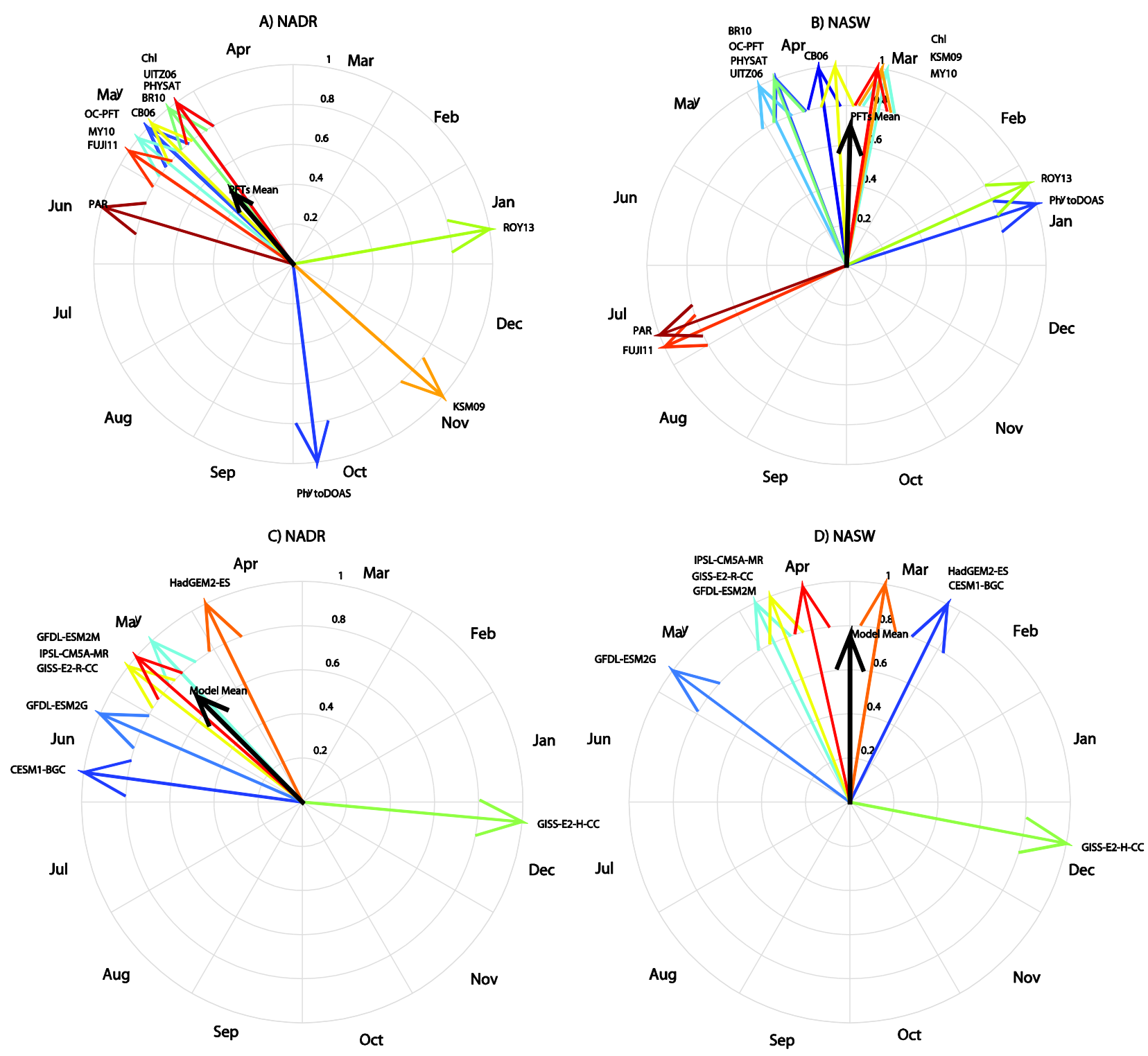

582 Figure 7. Months of maxima of the regionally binned PFT algorithm variables (Table 1)

583 (top panels - A and B) and CMIP5 models' diatom carbon biomass (bottom panels - C

584 and D). The following Longhurst (1998) provinces are displayed as examples: A and C)

585 North Atlantic Drift Region (NADR); B and D) The Western North Atlantic Subtropical

586 Gyral Province (NASW). See Supplement Fig. S9 for a map of the provinces. The black

587 arrow's direction indicates the PFT algorithms' or CMIP5 models' ensemble mean month 
of maximum (circular), and its length indicates one minus the circular variance in month

589 of maxima among the algorithms (an arrow length of one indicates zero variance, and an

590 arrow length of zero - maximal variance of one). The beginning of each month is

591 marked by the abbreviated month name on the polar plots. See Sect. 2.3 and

592 Supplement Part 4 for methodology details. Supplement Table S1 lists the CMIP5

593 models used with their acronyms as they appear here.

595 Further to the south, the NASW province straddles the $\mathrm{Chl}=0.08 \mathrm{mg} \mathrm{m}^{-3}$ climatological isoline 596 used here to delineate the gyre (Supplement Fig. S9) and is a typical northern-subtropical region.

597 It is mostly characterized by a single peak in most algorithms and exhibits some of the cleanest 598 seasonal cycles globally (Figs. 2A and 5A). It is considerably more oligotrophic and hence has

599 lower fraction of microplankton (and total Chl concentration) than NADR, year-round (cf. y-axis

600 scales of Fig. 6A vs. 6B). While some algorithms indicate a strong winter-spring peak (KSM09,

601 CB06), the annual range of others is a lot smaller and some even exhibit double peaks (ROY13,

602 FUJI11). Seven algorithms agree on a maximum for the primary bloom in March or April (Fig.

603 7B), but ROY13 and PhytoDOAS indicate a January peak, and FUJI11 indicates a July peak for 604 the primary bloom. Similarly, most CMIP5 models agree on a March or April bloom peak (Fig.

605 7D). As stated above, the DFT spectra of the satellite data (Supplement Fig. S10B) indicate that

606 overall variance is lower than NADR, and the first harmonic contains proportionately more

607 power than the second harmonic, indicating a single annual peak. A comparative analysis for

608 time-series at the Bermuda Atlantic Time Series (BATS) station, representative of the NASW

609 province and the Northern subtropics regime, is provided in Supplement Part 8 (Supplement Fig. 
610 S11), including discussion of some complementary in situ biogeochemical data. Supplement Part

6118 also provides details on mechanisms in the regions of interest discussed here.

612

613 In conclusion, regional binning of the satellite data sets reduces noise, and allows for inspection

614 of a limited number of actual time series from various regions. It also allows for analysis in

615 regions or algorithms that suffer from data sparsity (particularly true of the PHYSAT algorithm)

616 that precludes the DFT analysis on a per-pixel basis. On the other hand, if the chosen regions are

617 spatially heterogeneous, results may be misleading or meaningless, and regions may have an

618 arbitrary definition not necessarily relevant to the phenology at question here. Future monitoring

619 of biology and biogeochemistry at multiple specific representative locations such as BATS is

620 critically important for validation and inter-comparison of satellite algorithms.

621

$622 \quad 3.7$ Sources of Uncertainty

623 There are multiple sources of uncertainty that can affect the DFT phenology analysis presented,

624 both related to intrinsic ecosystem characteristics and features and limitations of the DFT

625 technique. Here we discuss some important considerations and we provide more details in

626 Supplement Part 9. The advantages of the DFT method include relative insensitivity to noise and

627 the ability to isolate the variance in the frequencies of interest for phenological studies (deBeurs

628 and Henebry, 2010). In addition, multi-year time series are summarized with a single metric

629 from the modeled signal and the DFT approach eliminates the need to consider a "sliding season"

630 to ensure the annual cycle is properly described everywhere (Racault et al., 2012). The DFT is a

631 statistical method to fit data to a sum of sines and cosines of fixed frequencies and varying

632 phases. As such, one disadvantage is that representation of seasonal cycles that have non- 
633 sinusoidal waveforms requires artificial placement of variance in high frequencies where most

634 noise resides. For example, Wilson and Qiu, 2008 observe sharp spikes in seasonal Chl blooms

635 in some areas of the oligotrophic gyres. If higher frequencies are present in the data, significant

636 aliasing can occur, confounding the analysis by placing spurious energy in lower frequencies.

637 The aliasing problem can be addressed by analyzing weekly or daily data to test for the

638 significance of higher order harmonics in the data. That said, Fourier analysis is among the best

639 available techniques to analyze cyclical phenomena and partition variance in frequency

640 components of interest, so it is strongly suited for analyzing seasonal cycles.

641

642 The correct retrieval of the phenological parameters of interest using the DFT technique was

643 verified in several ways: by examining an example time series (Supplement Fig. S1); by

644 validation against direct maxima finding via peak analysis of the time series of the monthly

645 climatologies of the respective PFT satellite data, and relating the results to percent seasonal

646 variance (Supplement Fig. S12); and by using the SeaWiFS PAR data set (as discussed in

647 Supplement Sect. S1). The overall assessment is that the DFT technique correctly identifies

648 phenological parameters if percent variance explained by the seasonal harmonics is $30 \%$ or more.

649 Phase derived by the DFT techniques in frequency bands where power density is low can be

650 stochastic and meaningless; therefore month of maxima determinations can be unreliable or

651 random and should be treated with caution in areas of low percent seasonal variance (Fig. 2;

652 Supplement Fig. S13). Supplement Fig. S12A illustrates the fraction of pixels for each algorithm

653 that exhibit a given percent seasonal variance. Comparison of direct maxima finding vs. the DFT

654 determinations of the month of maxima indicate that in places where percent seasonal variance

655 drops below $30 \%$, differences between the two methods can be $>2$ months for over $10 \%$ of the 
656 pixels for most algorithms (Supplement Fig. S12B). It was therefore determined that the DFT

657 technique results should be interpreted with caution or not used in analyses in places where

658 percent seasonal variance drops below 30\%. A map of the number of algorithms exhibiting

659 percent seasonal variance $<30 \%$ is shown in Supplement Fig. S13A, and the analogous map for

660 the CMIP5 models is shown in Supplement Fig. S13B. It is worth noting that analyzing

661 phenology in places with low percent seasonality becomes intrinsically meaningless, regardless

662 of what technique is used. Additionally, ensemble metrics for the PFT algorithms should be

663 interpreted with caution where few algorithms contribute to the mean (Supplement Fig. S6).

664 Finally, results should also be interpreted with caution at high latitudes where data can be sparse,

665 especially in the respective winter months. This is discussed in Supplement Sect. S1.

667 It is important to note that it is not exactly equivalent to analyze absolute biomass indicators (Chl, 668 carbon) and fractions (as done here for most PFT algorithms), e.g. there are indications that the 669 secondary bloom is more dominated by larger sizes than the primary peak (Cabré et al., 2016)

670 (see also Supplement Part 5 and Part 7). For example, a secondary peak can look about as high as

671 the primary one in terms of percent, but can be much weaker in terms of Chl. Mathematically, 672 percent microplankton can increase without an accompanying increase (or even with a decrease)

673 in total or microplankton absolute biomass or Chl. However, such situations are likely to be 674 atypical on a global scale according to modern ecosystem understanding. Absolute carbon 675 biomass of diatoms was analyzed for the CMIP5 models, which is not exactly equivalent to the 676 algorithm variables. Further analysis should focus on comparing phenology calculated from 677 fractions vs. absolute biomass indicators. Finally, physiological adaptation affects the Chl to 678 carbon ratio and can decouple $\mathrm{Chl}$ and carbon variability, especially in lower-latitude oceans (e.g. 
Behrenfelred et al., 2005; Siegel et al., 2013); it is best to express size-fractionated or PFT-

680 specific biomass in terms of carbon units, as done by Kostadinov et al., 2016 who re-cast the

681 PFTs in terms of carbon using the KSM09 particle size distribution algorithm and allometric 682 relationships (Menden-Deuer and Lessard, 2000). In spite of the above considerations, we stress 683 that the primary purpose of this work is PFT algorithm inter-comparison, and all PFT algorithms 684 are analyzed in an equivalent way here.

686 The phenological parameters described here were derived only from the large

687 phytoplankton/microplankton variable (Table 1) or for diatoms in the case of the CMIP5 models 688 and the PhytoDOAS and PHYSAT algorithms. While in much of the temperate, high latitude 689 and upwelling regions it is indeed larger phytoplankton that dominate the bloom, in the more 690 oligotrophic subtropics and tropics nanoplankton can dominate the seasonal maximum. Also, 691 diatoms can be found within the nanoplankton fraction or the microplankton can be dominated by 692 other large phytoplankton (e.g. dinoflagellates). Various PFT algorithms provide nanoplankton 693 and other PFT variables that need to be analyzed and compared in future work. The analysis 694 presented here is global; however, some algorithms were developed/parameterized with data sets 695 of specific limited geographic coverage. Those would not be expected to necessarily perform well 696 outside of their area of development. Notably, FUJI11 was developed for the Arctic. Not 697 surprisingly, this algorithm differs more substantially from other algorithms in the tropics and 698 subtropics. The Southern Ocean presents atypical bio-optical characteristics (e.g. Uitz et al., 699 2006) some implications of which are discussed in Supplement Part 9. 


\section{Concluding Remarks}

701 We used the Discrete Fourier Transform (DFT) to derive and inter-compare phenological

702 parameters for the 2003-2007 period among 1) the fraction of Chl corresponding to

703 microplankton (or a closely related variable) from 10 satellite ocean color algorithms, 2) satellite

704 determinations of chlorophyll concentration, and 3) diatom biomass from 7 CMIP5 climate

705 models. The phenological parameters derived were amplitude, month of maximum, percent

706 variance explained by the seasonal cycle, bloom duration, and secondary bloom characteristics.

707 Results indicate that PFT algorithms agree only to first order globally. Enough qualitative and

708 quantitative differences between the algorithms are detected (e.g. Fig. 6) to make a further

709 comprehensive, global validation exercise a high priority. While validation is outside the scope

710 of this work, a separate working group has been formed within the PFT Inter-comparison Project

711 to perform a comprehensive validation exercise (Bracher et al., 2015). Validation itself is

712 challenging (Brewin et al., 2011), as in situ HPLC-derived PFTs have their own limitations and

713 do not necessarily correspond to the way non-HPLC-based algorithms define their variables. To

714 allow for these subtle differences in the variables retrieved, it may be best to test all algorithms

715 against a comprehensive in situ data set incorporating co-located radiometric, bio-optical

716 (pigment concentration, IOPs) and derived biological quantities (phytoplankton Chl, size

717 structure, etc.) in order to resolve whether differences are due to algorithm uncertainties or to

718 actual biogeophysical differences between, for example, the timing of maximum diatom biomass

719 vs. maximum of large cells biomass (Bracher et al. 2015).

721 Comparison of phenological parameters in CMIP5 model output (diatom carbon biomass) to

722 those of satellite data suggests that the month of maximum is fairly well represented in models 
723 (albeit with a systematic, latitude-dependent bias), while other phenological characteristics show

724 a number of important biases in CMIP5 models: 1) more pronounced seasonal variability in the

725 models, e.g. a smoother latitudinal progression and less local spatial variability in phenological

726 indices such as month of maximum and bloom duration, 2) while seasonality in the satellite data

727 is cleanest (i.e. percent variance explained is highest) along a zonal band at $30^{\circ}$ latitude in both,

728 this feature is not reflected in the CMIP5 models. and 3) models exhibit a single annual biomass

729 peak over most of the ocean, except for the Equatorial band, whereas secondary blooms tend to

730 occur in zonal bands in temperate latitudes in the satellite data but are not well captured in the

731 climate models. These biases are probably due to over-simplification of processes in models and

732 a lower response to interannual variability than in reality as also discussed in Cabré et al. (2016).

733 Additionally, the coarse $1^{\circ}$ resolution does not allow a proper representation of coastal processes

734 and some frontal dynamics in models. We note that for many modelers, the PFT products

735 derived from satellite algorithms are considered as observations (not algorithm products per se)

736 and used as a reference for validating model outputs, (e.g. LeQuéré et al. (2005); Bopp et al.

737 (2005); Stock et al. (2014)). To improve the utility of satellite algorithms for this purpose, better

738 uncertainty characterization should be considered high priority.

739

740 A fruitful way forward would be to use algorithms of different theoretical bases together to

741 increase the degrees of freedom and solve for more variables. Advent of hyperspectral sensors in

742 the near future is expected to improve our ability to discern small spectral differences arising

743 from the different PFTs, as indicated, for example, by the development of the PhytoDOAS

744 algorithm. Therefore, future direction of efforts towards development of hyperspectral

745 algorithms is desirable, keeping in mind that there is a fundamental limit on the additional 
degrees of freedom available (Lee et al, 2007). While chlorophyll is certainly a useful variable, it

747 is carbon biomass in the living phytoplankton that is the variable of most direct relevance to

748 carbon cycle and biogeochemical studies; it is also the unit of PFT accounting in climate models

749 (Table S1). The carbon-based algorithm of Kostadinov et al. (2016) could be used in conjunction

750 with an algorithm partitioning Chl (e.g. BR10) in order to assess physiological status and

751 productivity by size class (Behrenfeld et al., 2005; Uitz et al., 2010).

752

753 Importantly, PFT algorithms and bio-optical algorithms in general could improve by moving

754 towards analytical approaches based more on first principles rather than empirical relationships,

755 i.e. being mechanistic in nature. Most of the existing PFT algorithms contain a high degree of

756 empiricism. Empirical algorithms rely on statistical relationships derived during a certain

757 environmental state and are thus not predictive in nature. Should the underlying relationship

758 change, the algorithm uncertainties will increase. Mechanistic models should remain more robust

759 under changing environmental conditions of the future, e.g. due to climate change.

\section{Acknowledgments}

761 This work was performed with funding from NASA Ocean Biology and Biogeochemistry

762 Program (grant \#NNX13AC92G to Irina Marinov and Tihomir S. Kostadinov). We thank Tilman

763 Dinter and Bernard Gentili for help with the PhytoDOAS and CB06 algorithm processing,

764 respectively, Amane Fujiwara for leading development of the FUJI11 algorithm, and Aurea Ciotti

765 for leading the development of the CB06 algorithm. We thank David Shields (specifically for

766 producing Supplement Fig. S11C and processing BATS data, and for work on the Chl gyre

767 contour lines), Svetlana Milutinović, and Danica Fine for providing help in the completion of this 
work. We thank Libe Washburn for FFT processing advice. We thank Jordan Rosenthal for his

769 compass plot labeling script (used here with modifications in Fig. 7). All data processing,

770 analysis and plotting for the phenological analysis in this work was done in MATLAB®. We

771 additionally acknowledge all the satellite algorithm providers (and their funding agencies) for

772 their support and providing their data. The coastlines displayed on maps were extracted with the

773 NOAA/NGDC GEODAS-NG software using the L1 layer of the GSHHG v2.2.3 (Wessel and

774 Smith, 1996) coastline data set. We acknowledge the World Climate Research Programme's

775 Working Group on Coupled Modelling, which is responsible for CMIP, and we thank the climate

776 modeling groups (listed in Table S1 of this paper) for producing and making available their

777 model output. For CMIP the U.S. Department of Energy's Program for Climate Model Diagnosis

778 and Inter-comparison provides coordinating support and led development of software

779 infrastructure in partnership with the Global Organization for Earth System Science Portals. We

780 are grateful to three anonymous reviewers and the editor whose comments and suggestions

781 improved the quality of this manuscript.

\section{References}

783 Alvain, S., Moulin, C., Dandonneau, Y., \& Bréon, F. M. (2005), Remote sensing of

784 phytoplankton groups in case 1 waters from global SeaWiFS imagery. Deep Sea Research Part I:

785 Oceanographic Research Papers, 52(11), 1989-2004.

786

787 Alvain, S., C. Moulin, Y. Dandonneau, and H. Loisel (2008), Seasonal distribution and

788 succession of dominant phytoplankton groups in the global ocean: A satellite view, Global

789 Biogeochem. Cycles, 22, GB3001, doi:10.1029/2007GB003154. 
791 Behrenfeld, M. J., E. Boss, D. A. Siegel, and D. M. Shea (2005), Carbon-based ocean

792 productivity and phytoplankton physiology from space, Global Biogeochem. Cycles, 19,

793 GB1006, doi:10.1029/2004GB002299.

794

795 Behrenfeld, M. J. (2010). Abandoning Sverdrup's critical depth hypothesis on phytoplankton

796 blooms. Ecology, 91(4), 977-989.

797

798 Bograd, S. J., D. G. Foley, F. B. Schwing, C. Wilson, R. M. Laurs, J. J. Polovina, E. A. Howell,

799 and R. E. Brainard (2004), On the seasonal and interannual migrations of the transition zone

800 chlorophyll front, Geophys. Res. Lett., 31, L17204, doi:10.1029/2004GL020637.

801 Bopp, L., Aumont, O., Cadule, P., Alvain, S., \& Gehlen, M. (2005). Response of diatoms

802 distribution to global warming and potential implications: A global model study. Geophysical

803 Research Letters, 32(19), L19606. doi:10.1029/2005GL023653

804 Bracher, A., Vountas, M., Dinter, T., Burrows, J. P., Röttgers, R., and Peeken, I. (2009),

805 Quantitative observation of cyanobacteria and diatoms from space using PhytoDOAS on

806 SCIAMACHY data, Biogeosciences, 6, 751-764, doi:10.5194/bg-6-751-2009.

807

808 Bracher N., Hardman-Mountford N., Hirata T., Bernard S., Brewin R., Bricaud A., Brotas V.,

809 Chase A., Ciotti A., Choi J.-K., Clementson L., Devred E., DiGiacomo P., Dupouy C., Kim W.,

810 Kostadinov T., Kwiatkowska E., Lavender S., Moisan T., Mouw C., Son S., Sosik H., Uitz J.,

811 Werdell J. , Zheng G. (2015) Report on IOCCG workshop "Phytoplankton composition from 
812 Space: towards a validation strategy for satellite algorithms” 25 - 26 Oct 2014, Portland, ME.,

813 USA, http://www.ioccg.org/groups/report-PFTworkshopOct2014.pdf; as NASA technical

814 Memorandum 217528_01-22-15 http://www.ioccg.org/groups/PFT-TM_2015-217528_01-22-

$815 \quad \underline{15 . p d f}$

816

817 Brewin, R. J., Sathyendranath, S., Hirata, T., Lavender, S. J., Barciela, R. M., \& Hardman-

818 Mountford, N. J. (2010), A three-component model of phytoplankton size class for the Atlantic

819 Ocean, Ecological Modelling, 221(11), 1472-1483.

820

821 Brewin, R. J., Hardman-Mountford, N. J., Lavender, S. J., Raitsos, D. E., Hirata, T., Uitz, J.,

822 Devred, E., Bricaud, A., Ciotti, A. and Gentili, B. (2011). An inter-comparison of bio-optical

823 techniques for detecting dominant phytoplankton size class from satellite remote sensing. Remote

824 Sensing of Environment, 115(2), 325-339.

825

826 Bricaud, A., A. M. Ciotti, and B. Gentili (2012), Spatial-temporal variations in phytoplankton

827 size and colored detrital matter absorption at global and regional scales, as derived from twelve

828 years of SeaWiFS data (1998-2009), Global Biogeochem. Cycles, 26, GB1010,

829 doi:10.1029/2010GB003952.

830

831 Cabré, A., I. Marinov ands S. Leung (2015), Consistent global responses of marine ecosystems

832 to future climate change across the IPCC AR5 earth system models, Clim Dyn 45: 1253.

833 doi:10.1007/s00382-014-2374-3.

834 
835 Cabré A., D. Shields, I. Marinov and T.S. Kostadinov (2016), Phenology of size-partitioned

836 phytoplankton carbon-biomass from ocean color remote sensing and CMIP5 models, Front. Mar.

837 Sci., 3:39. doi: 10.3389/fmars.2016.00039.

838

839 Campbell, J. W. (1995). The lognormal distribution as a model for bio-optical variability in the

840 sea. Journal of Geophysical Research: Oceans (1978-2012), 100(C7), 13237-13254.

841

842 Chisholm, S. W. (1992), Phytoplankton size. In P. G. Falkowski and A. D. Woodhead (Eds.),

843 Primary Productivity and Biogeochemical Cycles in the Sea. New York, Plenum Press, p. 213 -

844237.

845

846 Ciotti, A. M., \& Bricaud, A. (2006), Retrievals of a size parameter for phytoplankton and spectral

847 light absorption by colored detrital matter from water-leaving radiances at SeaWiFS channels in a

848 continental shelf region off Brazil, Limnology and Oceanography: Methods, 4, 237-253.

849

850 Cushing, D.H. (1959), The seasonal variation in oceanic production as a problem in population

851 dynamics. Journal du Conseil, 24 (3), 455-464.

852

853 Eppley, R. W., \& Peterson, B. J. (1979), Particulate organic matter flux and planktonic new

854 production in the deep ocean. Nature, 282, 677

855

856 Evans, G.T. and J. S. Parslow (1985), A Model of Annual Plankton Cycles, Biological

857 Oceanography, 3:3, 327-347. 
859 Falkowski, P.G., R.T. Barber, V. Smetacek (1998), Biogeochemical controls and feedbacks on 860 ocean primary production, Science, 281, 200-206.

861

862 Field, CB, Behrenfeld MJ, Randerson JT and Falkowski P (1998), Primary production of the

863 biosphere: Integrating terrestrial and oceanic components, Science, 281: 237-240.

864

865 Fujiwara, A., Hirawake, T., Suzuki, K., and Saitoh, S.-I. (2011), Remote sensing of size structure 866 of phytoplankton communities using optical properties of the Chukchi and Bering Sea shelf 867 region, Biogeosciences, 8, 3567-3580, doi:10.5194/bg-8-3567-2011.

868

869 Glover, D. M., J. S. Wroblewski, and C. R. McClain (1994), Dynamics of the transition zone in 870 coastal zone color scanner-sensed ocean color in the North Pacific during oceanographic spring,

871 J. Geophys. Res., 99, 7501-7511.

872

873 Habib, E. A. (2012). Geometric mean for negative and zero values. Int. J. Res. Rev. Appl. Sci, 11, $874 \quad 419-432$.

875

876 Hirata, T., Hardman-Mountford, N. J., Brewin, R. J. W., Aiken, J., Barlow, R., Suzuki, K., Isada, 877 T., Howell, E., Hashioka, T., Noguchi-Aita, M., and Yamanaka, Y., (2011), Synoptic

878 relationships between surface Chlorophyll-a and diagnostic pigments specific to phytoplankton

879 functional types, Biogeosciences, 8, 311-327, doi:10.5194/bg-8-311-2011. 880 
881 Hirata, T., N. Hardman-Mountford and R. J. W. Brewin, (2012), Comparing satellite-based

882 phytoplankton classification methods, Eos Trans. AGU, 93(6), 59.

883

884 Hirata, T. (2015), Satellite Phytoplankton Functional Type Algorithm Inter-comparison Project, 885 http://pft.ees.hokudai.ac.jp/satellite/index.shtml, last access: Oct. 16, 2015.

886

887 Hood, R. R., E.A. Laws, R.A. Armstrong, N.R. Bates, C.W. Brown, C.A. Carlson, F. Chai, S.C. 888 Doney, P.G. Falkowski, R.A. Feely, M.A.M. Friedrichs, M.R. Landry, J.K. Moore, D.M. Nelson, 889 T.L. Richardson, B. Salihoglu, M. Schartau, D.A. Toole, J.D. Wiggert (2006), Pelagic functional 890 group modeling: Progress, challenges and prospects, Deep-Sea Research II, 53, 459-512.

891

892 IOCCG (2014). Phytoplankton Functional Types from Space. Sathyendranath, S. (ed.), Reports 893 of the International Ocean-Colour Coordinating Group, No. 15, IOCCG, Dartmouth, Canada.

IPCC, 2013:Climate Change 2013: The Physical Science Basis. Contribution of Working Group I 896 to the Fifth Assessment Report of the Intergovernmental Panel on Climate Change [Stocker, T.F.,

897 D. Qin, G.-K. Plattner, M. Tignor, S.K. Allen, J. Boschung, A. Nauels, Y. Xia, V. Bex and P.M.

898 Midgley (eds.)]. Cambridge University Press, Cambridge, United Kingdom and New York, NY, 899 USA, $1535 \mathrm{pp}$.

900

901 Koeller, P., Fuentes-Yaco, C., Platt, T., Sathyendranath, S., Richards, A., Ouellet, P., ... \& 902 Aschan, M. (2009). Basin-scale coherence in phenology of shrimps and phytoplankton in the 903 North Atlantic Ocean. Science, 324(5928), 791-793. 
905 Kostadinov, T. S., D. A. Siegel, and S. Maritorena (2009), Retrieval of the particle size

906 distribution from satellite ocean color observations, J. Geophys. Res.,

907 doi:10.1029/2009JC005303.

908

909 Kostadinov, T. S., D. A. Siegel, and S. Maritorena (2010), Global variability of phytoplankton

910 functional types from space: assessment via the particle size distribution, Biogeosciences, 7(10),

$911 \quad 3239-3257$.

912

913 Kostadinov, T. S., Milutinović, S., Marinov, I., and Cabré, A. (2016), Carbon-based

914 phytoplankton size classes retrieved via ocean color estimates of the particle size distribution,

915 Ocean Sci., 12, 561-575, doi:10.5194/os-12-561-2016.

916

917 Le Quéré, C., S.P. Harrison, I. C. Prentice, E.T. Buitenhuis, O. Aumont, L. Bopp, H. Claustre, L.

918 Cotrim Da Cunha, R. Geider, X. Giraud, C. Klaas, K.E. Kohfeld, L. Legendre, M. Manizza, T.

919 Platt, R.B. Rivkin, S. Sathyendranath, J. Uitz, A.J. Watson, D. Wolf-Gladrow (2005), Ecosystem

920 dynamics based on plankton functional types for global ocean biogeochemistry models. Global

921 Change Biology 11, 2016-2040.

922

923 Lee, ZhongPing, Kendall Carder, Robert Arnone and MingXia He (2007), Determination of

924 Primary Spectral Bands for Remote Sensing of Aquatic Environments. Sensors 2007, 7, 3428-

9253441.

926 
927 Levy, M., Lehahn, Y., Andre, J. M., Memery, L., Loisel, H., and Heifetz, E. (2005), Production

928 regimes in the northeast Atlantic: A study based on Sea-viewing Wide Field-of-view Sensor

929 (SeaWiFS) chlorophyll and ocean general circulation model mixed layer depth. J. Geophys. Res.

930 110. doi:10.1029/2004jc002771.

931

932 Loisel, H., J.-M. Nicolas, A. Sciandra, D. Stramski, and A. Poteau (2006), Spectral dependency

933 of optical backscattering by marine particles from satellite remote sensing of the global ocean, $J$.

934 Geophys. Res., 111, C09024, doi:10.1029/2005JC003367.

935

936 Longhurst, A.R. (1998). Ecological Geography of the Sea. Academic Press, San Diego. 397p.

937

938 McClain, C.R. (2009), A decade of satellite ocean color observations, Annual Review of Marince

939 Science, 1, 19-42.

940

941 Marañón, E. (2015), Cell Size as a Key Determinant of Phytoplankton Metabolism and

942 Community Structure, Annu. Rev. Mar. Sci., 7(1), doi: 10.1146/annurev-marine-010814-015955.

943

944 Menden-Deuer S. and Lessard EJ (2000), Carbon to volume relationships for dinoflagellates,

945 diatoms, and other protist plankton, Limnol. Oceanogr., 45: 569-579.

946

947 Mouw, C. B., and J. A. Yoder (2010), Optical determination of phytoplankton size composition

948 from global SeaWiFS imagery, J. Geophys. Res., 115, C12018, doi:10.1029/2010JC006337.

949 
950 NASA Goddard Space Flight Center, Ocean Biology Distributed Active Archive Center; (2010):

951 Sea-viewing Wide Field-of-view Sensor (SeaWiFS) Ocean Color Data, NASA OB.DAAC,

952 Greenbelt, MD, USA. Reprocessing R2010.0. Maintained by NASA Ocean Biology Distributed

953 Active Archive Center (OB.DAAC), Goddard Space Flight Center, Greenbelt MD.

954

955 NCEI: National Centers for Environmental Information (NOAA) (2015), Registration of

956 Structured Square-Cell Grids, URL:

957 https://www.ngdc.noaa.gov/mgg/global/gridregistration.html, last accessed: Dec. 8, 2015.

958

959 O’Reilly, J.E., Maritorena, S., Mitchell, B.G., Siegel, D.A., Carder, K.L., Garver, S.A., Kahru,

960 M., McClain, C. (1998), Ocean chlorophyll algorithms for SeaWiFS, J. Geophys. Res. 103(C11):

$96124,937-24,953$.

962

963 O’Reilly, J.E., Maritorena, S., Siegel, D.A., O’Brien, M.C., Toole, D., Mitchell, B.G., et al.

964 (2000). Ocean color chlorophyll-a algorithms for SeaWiFS, OC2, and OC4: version 4, SeaWiFS

965 postlaunch calibration and validation analyses, Part 3, NASA/TM 206892, 11, 9-23.

966

967 Platt, T., Fuentes-Yaco, C., \& Frank, K. T. (2003). Marine ecology: spring algal bloom and larval

968 fish survival. Nature, 423(6938), 398-399.

969 Platt, T., White III, G. N., Zhai, L., Sathyendranath, S., \& Roy, S. (2009). The phenology of

970 phytoplankton blooms: Ecosystem indicators from remote sensing. Ecological Modelling,

$971220(21), 3057-3069$.

972 
973 Racault, M. F., Le Quéré, C., Buitenhuis, E., Sathyendranath, S., \& Platt, T. (2012).

974 Phytoplankton phenology in the global ocean. Ecological Indicators, 14(1), 152-163.

975

976 Roy, S., Sathyendranath, S., \& Platt, T. (2011), Retrieval of phytoplankton size from bio-optical

977 measurements: theory and applications, Journal of The Royal Society Interface, 8(58), 650-660.

978

979 Roy, S., Sathyendranath, S., Bouman, H., \& Platt, T. (2013), The global distribution of

980 phytoplankton size spectrum and size classes from their light-absorption spectra derived from

981 satellite data, Remote Sensing of Environment, 139, 185-197.

982

983 Sadeghi A., Dinter T., Vountas M., Taylor B., Peeken I., Altenburg Soppa M., Bracher A. (2012),

984 Improvements to the PhytoDOAS method for identification of coccolithophores using hyper-

985 spectral satellite data. Ocean Sciences 8: 1055-1070.

986

987 Sapiano, M. R. P., C. W. Brown, S. Schollaert Uz, and M. Vargas (2012), Establishing a global

988 climatology of marine phytoplankton phenological characteristics, J. Geophys. Res., 117,

989 C08026, doi:10.1029/2012JC007958.

990

991 Sieburth, J. M., V. Smetacek, and J. Lenz (1978), Pelagic ecosystem structure: heterotrophic

992 compartments of the plankton and their relationship to plankton size fractions, Limnol.

993 Oceanogr., 23, 1256-1263.

994 
995 Siegel, D. A., Doney, S. C., \& Yoder, J. A. (2002). The North Atlantic spring phytoplankton

996 bloom and Sverdrup's critical depth hypothesis. science, 296(5568), 730-733.

997

998 Siegel, D. A., M. J. Behrenfeld, S. Maritorena, C. R. McClain, D. Antoine, S. W. Bailey, P. S.

999 Bontempi, E. S. Boss, H. M. Dierssen, S. C. Doney, R. E. Eplee Jr, R. H. Evans, G. C. Feldman,

1000 E. Fields, B. A. Franz, N. A. Kuring, C. Mengelt, N. B. Nelson, F. S. Patt, W. D. Robinson, J. L.

1001 Sarmiento, C. M. Swan, P. J. Werdell, T. K. Westberry, J. G. Wilding, and J. A. Yoder (2013),

1002 Regional to global assessments of phytoplankton dynamics from the SeaWiFS mission, Remote

1003 Sensing of Environment, 135(0), 77-91.

1004

1005 Siegel, D. A., K. O. Buesseler, S. C. Doney, S. F. Sailley, M. J. Behrenfeld, and P. W. Boyd

1006 (2014), Global assessment of ocean carbon export by combining satellite observations and food-

1007 web models, Global Biogeochem. Cycles, 28, 181-196, doi:10.1002/2013GB004743.

1008

1009 Stock, Charles A., John P. Dunne, Jasmin G. John (2014), Global-scale carbon and energy flows

1010 through the marine planktonic food web: An analysis with a coupled physical-biological model,

1011 Progress in Oceanography, Volume 120, Pages 1-28, doi: 10.1016/j.pocean.2013.07.001.

1012

1013 Uitz, J., H. Claustre, A. Morel, and S. B. Hooker (2006), Vertical distribution of phytoplankton

1014 communities in open ocean: An assessment based on surface chlorophyll, J. Geophys. Res., 111, 1015 C08005, doi:10.1029/2005JC003207.

1016 
1017 Uitz, J., H. Claustre, B. Gentili, and D. Stramski (2010), Phytoplankton class- specific primary

1018 production in the world's oceans: Seasonal and interannual variability from satellite observations, 1019 Global Biogeochem. Cycles, 24, GB3016, doi:10.1029/2009GB003680.

1020

1021 Vidussi, F., H. Claustre, B. B. Manca, A. Luchetta, and J. C. Marty (2001), Phytoplankton

1022 pigment distribution in relation to upper thermocline circulation in the eastern Mediterranean Sea

1023 during winter, J. Geophys. Res., 106(C9), 19,939-19,956.

1024

1025 Wessel, P., and W. H. F. Smith, A (1996), Global Self-consistent, Hierarchical, High-resolution

1026 Shoreline Database, J. Geophys. Res., 101, \#B4, pp. 8741-8743.

1027

1028 Wilson, C., \& Qiu, X. (2008). Global distribution of summer chlorophyll blooms in the

1029 oligotrophic gyres. Progress in Oceanography, 78(2), 107-134. 